Florida International University FIU Digital Commons

$11-13-2008$

\title{
Improving concept learning in green building by addressing students' learning styles and prior knowledge
}

Sreelatha Chunduri

Florida International University

DOI: $10.25148 /$ etd.FI14060826

Follow this and additional works at: https://digitalcommons.fiu.edu/etd

Part of the Construction Engineering Commons, and the Construction Engineering and Management Commons

\section{Recommended Citation}

Chunduri, Sreelatha, "Improving concept learning in green building by addressing students' learning styles and prior knowledge" (2008). FIU Electronic Theses and Dissertations. 2356.

https://digitalcommons.fiu.edu/etd/2356 
FLORIDA INTERNATIONAL UNIVERSITY

Miami, Florida

IMPROVING CONCEPT LEARNING IN GREEN BUILDING BY ADDRESSING

STUDENTS' LEARNING STYLES AND PRIOR KNOWLEDGE

A thesis submitted in partial fulfillment of the

requirements for the degree of

MASTER OF SCIENCE

in

CONSTRUCTION MANAGEMENT

by

Sreelatha Chunduri 
College of Engineering and Computing

This thesis, written by Sreelatha Chunduri, and entitled Improving Concept Learning in Green Building by Addressing Students' Learning Styles and Prior Knowledge, having been approved in respect to style and intellectual content, is referred to you for judgment.

We have read this thesis and recommend that it be approved.

Syed M. Ahmed

M. Emre Bayraktar

Yimin Zhu, Major Professor

Date of Defense: November 13, 2008

The thesis of Sreelatha Chunduri is approved.

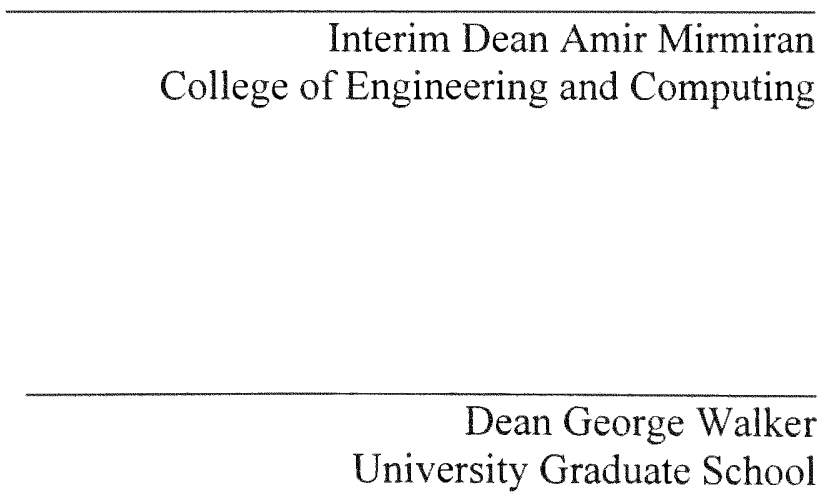

Florida International University, 2008 


\section{DEDICATION}

I dedicate this thesis to my mother C. Leelavathi and my father C. R. Prasad. Without their love, patience, understanding, and support I would have not been able to complete this work. 


\section{ACKNOWLEDGMENTS}

I would like to express my sincere gratitude to my advisor, Professor Yimin Zhu. Without his persistent help and guidance this thesis would not have been possible. He assisted me in numerous ways by taking great effort in explaining the difficult parts of the work and by making the required corrections. I thank him for sharing his knowledge and helping me in developing my ideas in this field.

I thank Professor Syed Ahmed and Professor Emre Bayraktar, for the participation and useful suggestions in this work. I am also grateful to Mr. Dhanunjaya for helping me. 


\section{ABSTRACT OF THE THESIS \\ IMPROVING CONCEPT LEARNING IN GREEN BUILDING BY ADDRESSING \\ STUDENTS' LEARNING STYLES AND PRIOR KNOWLEDGE}

by

Sreelatha Chunduri

Florida International University, 2008

Miami, Florida

Professor Yimin Zhu, Major Professor

In green building there is a requirement for the collaboration of students from different disciplines in order to solve challenging problems. Successful collaboration depends on the establishment of a common understanding of the subject matter among those involved. To gain common understanding concept learning is critical. A concept learning process may be improved when factors affecting it are addressed. Prior knowledge and learning styles of the students may influence the way they learn concepts. This thesis is focused on studying the relationship between a concept learning process and prior knowledge and learning styles of students. An experiment was conducted by giving students concepts customized to their prior knowledge and learning styles. Tests were conducted at various stages and they were statistically analyzed with t-tests to determine if a difference existed between the two groups. The results indicated that the group which was given the customized material showed improvement in their concept learning over the group who were taught conventionally. 


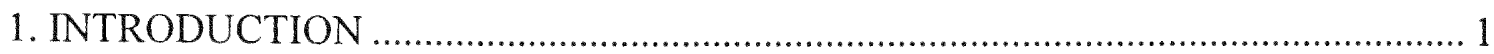

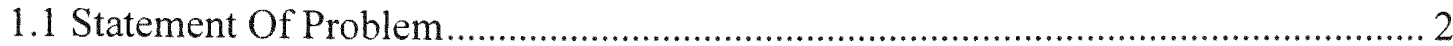

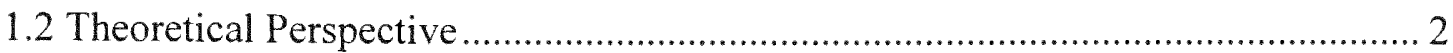

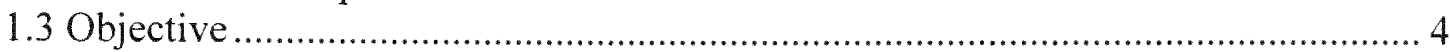

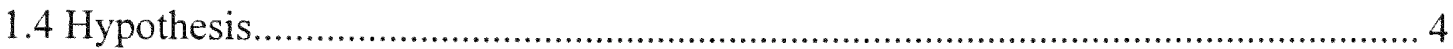

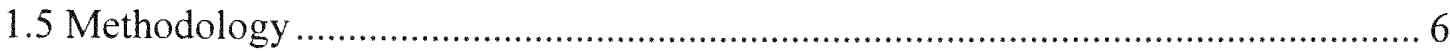

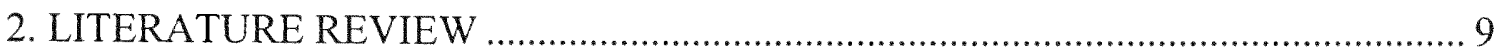

2.1 Multidisciplinary Collaboration in AEC and Green Building ............................... 9

2.2 Prior Knowledge and its Impact on a Collaborative Environment ........................ 10

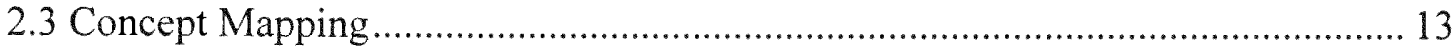

2.3.1 Concept Mapping as an Assessment Tool .................................................. 15

2.3.2 Concept Map Scoring Techniques ............................................................... 17

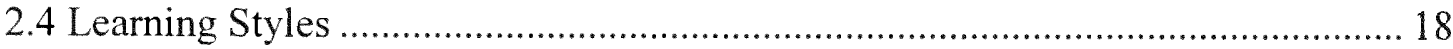

2.4.1 Importance of Learning Styles .................................................................. 19

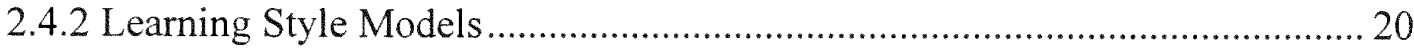

2.4.3 Learning Styles in Practice ......................................................................... 21

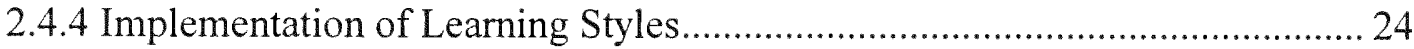

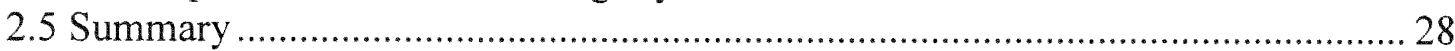

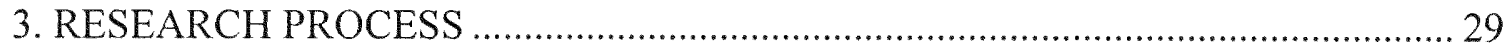

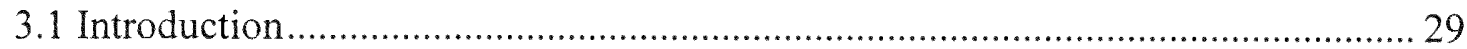

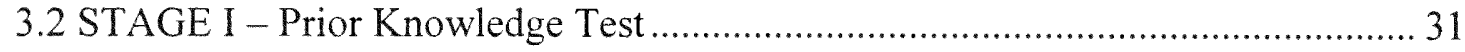

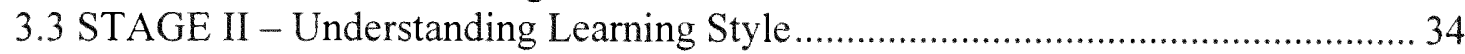

3.4 STAGE III - Concept Presentations Based on Learning Styles ............................ 36

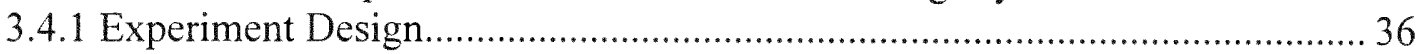

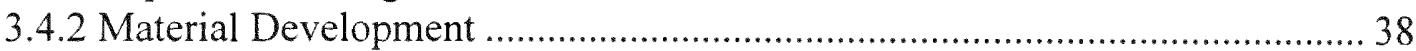

3.5 STAGE IV - Final Evaluation of Concept Development.................................... 40

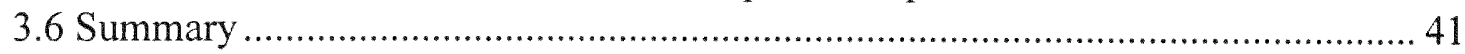

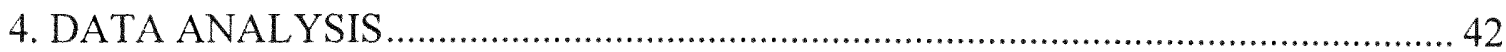

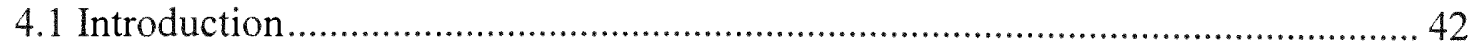

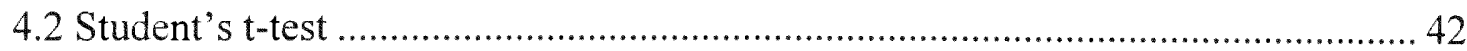

4.2.1 Interpretation of output from independent-samples t-test............................. 43

4.2.2 Calculating the effect size for independent-samples t-test ........................... 45

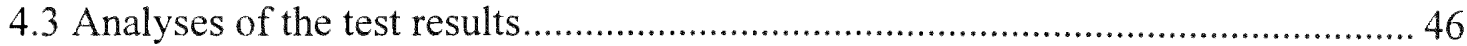

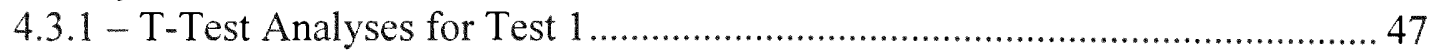

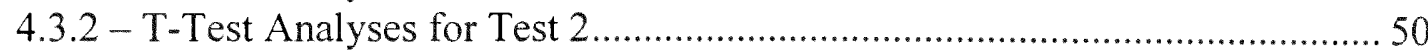

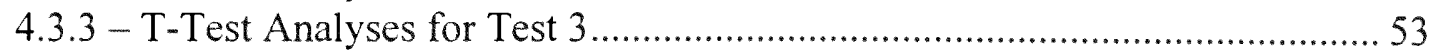

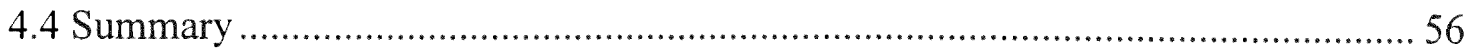




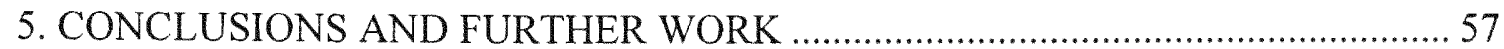

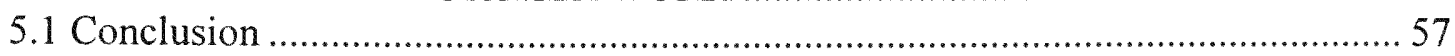

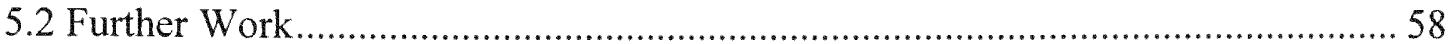

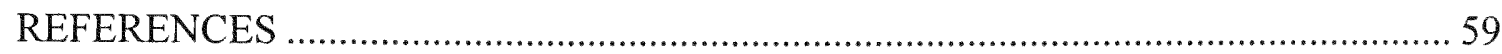

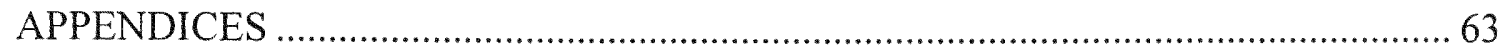




\section{LIST OF TABLES}

TABLE

Table 1 Pros and Cons of the two mapping techniques............................... 17

Table 2 Stages of Research.......................................................... 30

Table 3 Students based on their learning style modality ................................

Table 4 Group A and Group B division...............................................37

Table 5 Descriptive statistics concerning the variables..............................43

Table 6 Independent samples test.............................................44

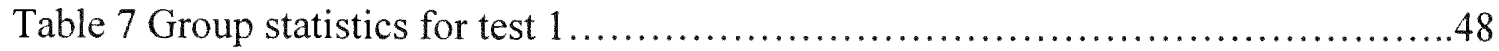

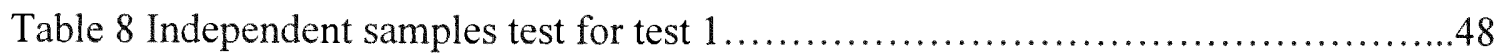

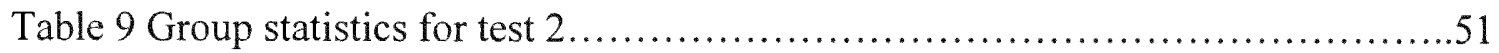

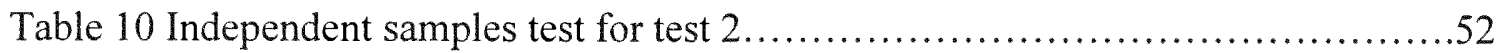

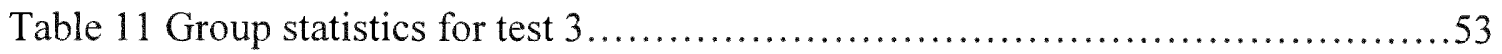

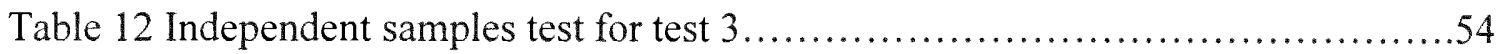




\section{LIST OF FIGURES}

FIGURE

PAGE

Figure 1 Process chart for the validation procedure .................................6

Figure 2 Simple concept map with the concepts of a green building...................14

Figure 3 Fill-in-the map having two concepts and four linking words as blanks..........16

Figure 4 Percentage of students from different undergraduate degrees.................30

Figure 5 Expert concept map with the different disciplines color coded.................33

Figure 6 Pie Chart showing the different types of learners in BCN 5728 class...........35

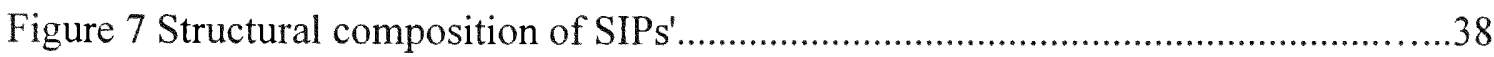

Figure 8 Presentation of concepts of the structural properties of SIPs' for group 'A'

Figure 9 Scores compared in group A and group B................................47

Figure 10 Material presentation and the areas where the groups scored higher...........50 


\section{CHAPTER 1}

\section{INTRODUCTION}

Integration of knowledge from different disciplines is often required to resolve unique and complex interdisciplinary problems such as those in green building. Interdisciplinary work typically integrates methods and concepts of multiple disciplines to create new knowledge (Borrego, 2007). Learning concepts from different disciplines has become an important factor to be considered in many professional and educational sectors, including the AEC (Architecture Engineering Construction) industry that is striving for the development and implementation of new technology for solving complex problems in the real world. This challenge also acts as an impetus and urges individuals to work effectively with people from other disciplines.

Interdisciplinary teamwork demands effective collaboration in order to develop a common understanding of a problem or toward the solution to the problem. Although many studies have pointed out that communication and sharing knowledge helps the process of developing such a common understanding, learning is an individual process. During the process of teamwork, the learning needs of each individual need to be addressed. The way in which information is communicated to each individual is important because the reception of information by each student may not be effective if information is not presented to the student's learning style. 
Apart from learning styles, effective learning is built on a student's prior knowledge. The development of new concepts needs to be established from a student's existing concepts. Thus, there is a need to better understand the relation between effective concept learning in multidisciplinary studies, the impact of learning styles and background knowledge.

\subsection{STATEMENT OF PROBLEM}

Green building is a process involving parties from many different disciplines. The success of a green building project depends on the effective collaboration of students who can establish a common understanding of problems and solutions. Many studies have focused on developing multidisciplinary courses to help students learn how to work effectively in a multidisciplinary team environment. One of the problems related to multidisciplinary learning is that students have different learning styles and prior knowledge. So, the challenge is to create an effective learning environment, which caters to the individual's innate learning style and prior knowledge.

\subsection{THEORETICAL PERSPECTIVE}

Interdisciplinary education and research have gained prominence in the last two decades. Many universities are investing huge amounts of money and time in interdisciplinary research and interdisciplinary programs. Individuals are provided with extensive training, which helps them work across disciplines and make them think more innovatively and strategically. The need for interdisciplinary education is inevitable in 
this modern era in order to provide efficient solutions to ever growing complexity and uniqueness of problems (Borrego, 2007).

Interdisciplinary approaches are common in many disciplines such as AEC (Architects/Engineers/Constructors), health care and natural resource management. In AEC the "master builders atelier" model is often applied to bring the AEC disciplines together in an information age setting. Correspondingly, a multidisciplinary course in AEC takes a multisite, cross disciplinary, project-based and team oriented approach to teaching and learning (Fruchter, 1999). An interdisciplinary team refers to a team whose members work together closely and communicate frequently to optimize a design (Hall 2001). The expansion of multidisciplinary education in graduate and undergraduate programs can help future scientists and managers to deal more effectively with complex problems in green building (Ewel, 2000). Therefore, there is a definite need for interdisciplinary education and an effective teaching method to teach multidisciplinary students in a collaborative environment.

Prior knowledge and the learning style of students are two of the elements to be addressed in multidisciplinary learning. The students should be nurtured with the concepts which act as building blocks of a discipline. Concept maps greatly help in bridging gaps between disciplines and bringing individuals to a common understanding of a subject matter (Sims-Knight, 2004). Concept maps can be broadly classified as network diagrams in which concepts are nodes and the interrelationship between concepts are represented by labeled links. Concepts maps have been proved as successful 
teaching aids and assessment tools (Sims-Knight, 2004). Further research indicates that teachers are able to use student created concepts maps to identify those specific areas within the curriculum that should be modified in order to promote greater understanding of the subject matter (Sims-Knight, 2004).

Each student has his/her own style of learning, which is influenced by many factors (psychological, educational, adaptation to new environments, etc.). As stated by some psychologists, "Learning means different things to different people." Researchers (e.g.; Fernald, Keller, Dunn, Orton, Gillingham, Stillman, Montessori etcetera) recognized that people learn in different ways. Thus, the students' learning style and prior knowledge influences the way in which they learned the concepts. It is a challenging task to create an environment keeping all these aspects in mind.

\subsection{OBJECTIVE}

The objective of the research is to better understand the relationship between students' concept learning in green building and the learning materials that are tailored-to students' learning styles and prior knowledge.

\subsection{HYPOTHESIS}

The experimental population is composed of students from multidisciplinary backgrounds in architecture, construction and civil engineering. The students will be divided into two groups, $\mathrm{A}$ and $\mathrm{B}$, with approximately 20 in each group. The population 
undergoing the experiment is measured by $\mu$, which is the mean score representing the accuracy of student's knowledge of a concept. Group A students are measured by the statistical variable $\mu_{\mathrm{a}}$ and will learn a set of concepts related to green building with learning materials prepared by the researcher. Group B students are measured by the variable $\mu_{\mathrm{b}}$ and will learn the same concepts in the conventional format, e.g., text books or notes.

The research hypothesis is denoted by $\mathrm{H}_{1}$ and the null hypothesis is denoted by $\mathrm{H}_{0}$.

$\mathrm{H}_{1}$ : The students who gain the knowledge with the concepts tailored to their learning style will learn better than the students who learn in the conventional method.

$\mathrm{H}_{0}$ : The students who gain the knowledge with the concepts tailored to their learning style will learn the same or worse than the students who learn in the conventional method.

The study hypothesizes that,

$$
\begin{aligned}
& \mathrm{H}_{1}: \mu_{\mathrm{a}}>\mu_{\mathrm{b}} \\
& \mathrm{H}_{0}: \mu_{\mathrm{a}} \leq \mu_{\mathrm{b}}
\end{aligned}
$$




\subsection{METHODOLOGY}

The following figure is a process chart, which depicts the procedure of the research process.

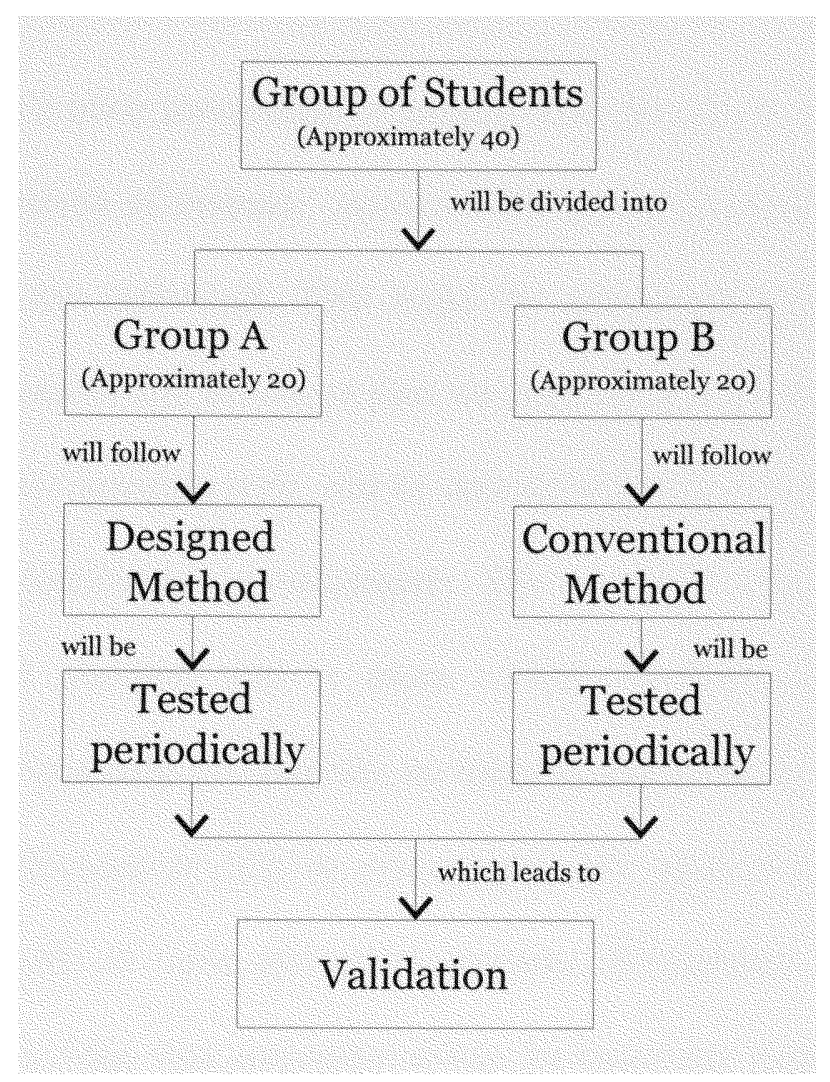

Figure 1: Process chart for the validation procedure

\section{Conventional Method:}

This is the typical pedagogical way in which concept learning takes place irrespective of the student's background knowledge and learning style. The learning environment could be either in the form of lectures in a classroom or in the form of online teaching. Materials such as textbooks or notes assigned by the researcher are 
presented to the students and their understanding to a specific set of concepts is tested accordingly by using test methods such as multiple choice questions.

\section{Designed Method:}

Step 1: The student's prior knowledge is gauged with the aid of an expert concept map and a test. A comparison of students' answers with an expert concept map will show the knowledge gap of the individual. This helps the researcher understand the student's existing knowledge status and develop a plan for learning new concepts.

Step 2: Each student's learning style will be determined with the help of a learning style (visual, auditory, kinesthetic) questionnaire. The students with visual style will be presented with the material that is more visual. Auditory learners are good at communicating and listening to materials, so these students will be given lectures on the subject and group discussions will be encouraged. The student will be asked to learn concepts with the help of tapes and online lectures. Kinesthetic learners can learn by hands on experience. They can remember things by touching, feeling and experiencing. These types of students will be educated with the help of concrete concepts such as computer generated objects and simulations, and problem-solving exercises.

Step 3: The concepts presented to students will be structured to the student's learning style, and they will be tested by using conventional test methods such as multiple choices. Step 4: Final validation will be done by statistically analyzing the test scores of Group A and Group B. 


\section{Comparison Plan:}

The idea behind testing the students by dividing into two groups ( $\mathrm{A}$ and $\mathrm{B}$ ) is to compare their performance when the study materials are presented in conventional and designed format. The comparison of results of both the groups which are tested at the beginning and ending will help in understanding the differences between the two approaches. The steps included are as follows:

- First step is to test the prior knowledge of both the groups. Later the designed group (A) will be given learning materials tailored to their prior knowledge, and the conventional group (B) will be given materials irrespective of their prior knowledge - This step will help in understanding the role of prior knowledge on students.

- Second step in the plan is to identify the learning styles of both the groups and give group A with designed materials and group B with conventional material This step will help in understanding the role of learning styles on the student.

- After the learning styles and prior knowledge of each student is understood, study material will be given accordingly.

- The final step is to test the improvement in the students' concept learning process - This step will help in understanding the role of prior knowledge and learning styles on the students' concept learning process.

The above steps will help in either supporting or failing to support the research hypothesis. The research hypothesis is examine if group A (who are given the designed material) will perform well than group B (who are given conventional material). 


\section{CHAPTER 2}

\section{LITERATURE REVIEW}

\subsection{MULTIDISCIPLINARY COLLABORATION IN AEC AND}

\section{GREEN BUILDING}

Students in the AEC (Architecture - Engineering - Construction) are required to work collaboratively in a multidisciplinary environment. Team members develop their design solutions independently as well as collaboratively (Fruchter, 1999). Building design and construction processes are going "green." High performance in buildings can be achieved only through integrated design approaches that consider various systems (structural, lighting, telecommunication, HVAC, controls, facades, interiors) as integral parts of spaces, and aims to provide flexible, adaptable, environmentally sustainable spaces (Ilal, 2007).

Collaboration among team members in AEC environments is necessary as the information is shared across disciplines. Students are trained in their specific discipline such that they know very little about how others perform their work or the information requirement by others to do their tasks (O'Brien, 2003). There is a pedagogical need to enhance traditional methods in order to monitor and evaluate the evolution of the crossdisciplinary learning experience students have in multidisciplinary project-based courses such as the AEC course (Fruchter, 1999). According to Skinner (2001) "Multidisciplinary 
refers to different disciplines involved in the same task and working alongside each of them but functioning independently."

\subsection{PRIOR KNOWLEDGE AND ITS IMPACT ON A}

\section{COLLABORATIVE ENVIRONMENT}

Students in the AEC domain come from different disciplines and may have different perceptions of concepts in the domain. This can be observed in the green building education. The students work collaboratively in order to attain the knowledge of concepts pertaining to the green building. Student collaboration involves the interaction among construction, architectural, mechanical, structural and other disciplinary students. Collaboration among multidisciplinary students can be successfully achieved if they are knowledgeable about concepts of the different disciplines involved in it.

The concepts students have in their mind impact the way they learn new concepts. Students can develop new knowledge structure based on their prior knowledge. Student from a particular disciplinary background may have prior knowledge of concepts, which might be completely different from that of a student from a different discipline. Prior knowledge influences learning of an individual, and learners construct concepts from prior knowledge (Resnick, 1983; Glaserfeld, 1984). New concepts are best learned when teachers uncover and address pre-existing knowledge that their students bring with them (Brown, 2003). 
The impact of prior knowledge on the current knowledge may lead to incorrect interpretations or misunderstandings of an idea, concept, or process. These incorrect interpretations can be categorized as follows (Committee on Undergraduate Science Education, 1997):

- Preconceived notions: forming an opinion prior to actual knowledge or experience.

- Non-scientific beliefs: from religious or mythical teachings.

- Conceptual misunderstandings: incomplete or over-simplified knowledge from previous courses.

- Vernacular misconceptions: uncertainty about differences between the popular vs. the scientific use of words like work and theory.

- Factual misconceptions: falsities learned at an earlier time and retained.

Educators should understand the effect of prior knowledge in order to help students make the most out of their new experience (Roschelle, 1995). David Ausbel (1968) who is an educational psychologist, said, "the most important single factor influencing learning is what the learner already knows. Ascertain this and teach them accordingly." Prior knowledge can be explained as a combination of the learner's attitudes, experiences, and knowledge (Kujawa \& Huske, 1995). Students have a range of prior knowledge, skills, beliefs, and concepts that significantly influence what they notice about the environment and how they organize and interpret it. This affects their abilities to remember, reason, solve problems, and acquire new knowledge. 
Roschelle (1995) described in his paper that "educators often focus on the ideas that they want their audience to have. But research has shown that a learner's prior knowledge often confounds an educator's best efforts to deliver ideas accurately. Prior knowledge can be at odds with the presented material, and consequently, learners will distort presented material. Neglect of prior knowledge can result in the audience learning something opposed to the educator's intentions, no matter how well those intentions are executed in an exhibit, book, or lecture."

When assessing learning outcome, the structure of a student's prior knowledge may negate the effect of collaborative knowledge construction. It is not enough to simply provide learners with a collaborative learning environment. The collaborative learning process and outcomes can be improved greatly when appropriate additional support is provided (Ertl \& Mandl, 2006). "Collaborative learning" refers to an instruction method in which students at various performance levels work together towards a common goal (Gokhale, 1995). The collaborative learning scenarios rely heavily on learner's prerequisites. Carefully designed learning environments may balance out the differences in learners' individual prerequisites. Collaboration is more than simply a stimulus for an individual's cognitive processes (Ertl \& Mandl, 2006). According to Gokhale, (1995), collaborative learning can be effective if the instructor views teaching as a process of developing students' abilities to learn. The instructor's role is not to transmit information, but to serve as a facilitator for learning. 
Research conducted by Ertl and Mandl (2006) indicated that both an individual's prior knowledge as well as the quality of collaborative knowledge construction strongly impact individual learning outcomes. The effects of prior knowledge in collaboration indicate that an individual's prior knowledge influences learning outcomes in the collaborative learning context (O'Donnell \& Dansereau, 2000). Thus, it is very important to consider learners' prior knowledge in a collaborative environment.

\subsection{CONCEPT MAPPING}

Concept map is an educational tool which has the ability to delve into a learner's cognitive structure and show both the learner and the teacher what the learner already knows (Novak \& Gowin, 1984). Concept mapping is a knowledge representation tool which was developed in 1972 by Joseph D. Novak (based on Ausbel's work on meaningful learning) in his research program at Cornell University (Novak, 1998). It is a useful device for helping students learn about the structure of knowledge and the process of knowledge production (Novak \& Gowin, 1984). It is composed of concepts, and the relationship between them is indicated by a connecting line between two concepts. Novak and Canas (2006) defined concept as a perceived regularity in events or objects, or records of events or objects, designated by a label. For example, "Building" is the label people use to designate an object enclosed with walls, roof and windows. "Energy" is the label people use for the event that involves the capacity for work or vigorous activity. Two or more concepts connected using linking words or phrases to form a meaningful statement are propositions. For example, "green building is energy efficient and reduces environmental impact" can be represented by a simple concept map forming valid 
proposition about the concepts "green building", "energy efficiency" and "environmental impact". Figure 2 shows a simple concept map with the three mentioned concepts.

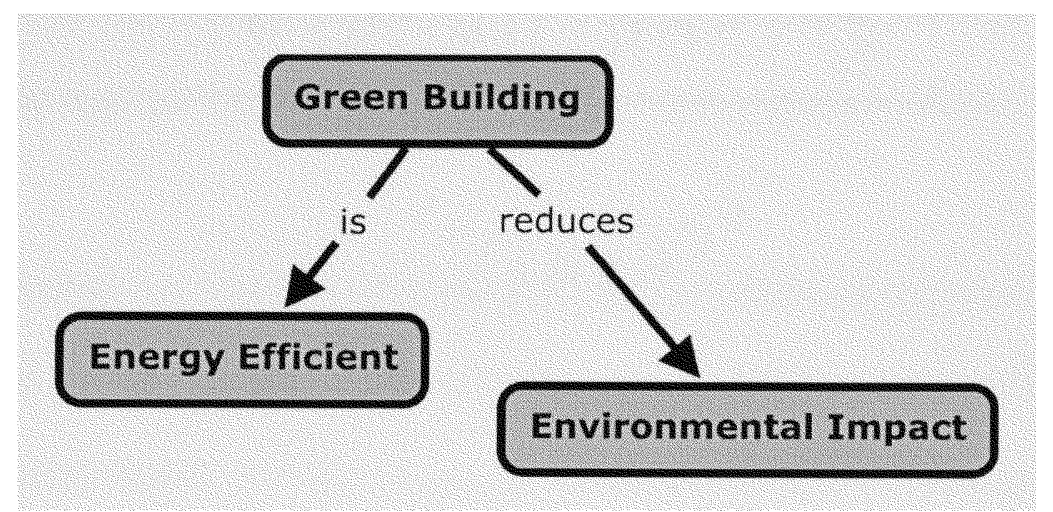

Figure 2: Simple concept map with the concepts of a Green Building

Concepts are represented in a hierarchical fashion with the most general concepts at the top and the less general concepts at the bottom (Novak and Canas 2006). Cross links show meaningful connections between one segment of the concept hierarchy and other segments (Novak and Gowin 1984). Concept maps helps in testing the knowledge gap of the students. The student's concept map can be compared to an expert concept map. A map prepared by an individual who is an expert in a particular field is called expert concept map. By comparing the student's map with the expert map, the concepts that are missing in the student's map can be identified and knowledge can be imparted accordingly. Concept mapping is a powerful tool for observing the subtle or slight degree of differences a student holds for concepts embedded in their map. These differences can be assessed and scored which will be discussed in the following paragraphs. 


\subsubsection{Concept Mapping as an Assessment Tool}

Concept mapping can be used as an assessment tool as it can measure the student's level of knowledge. There are two concept mapping techniques, one is the construct-a-map approach and other is the fill-in-the map approach (Primo et al., 1998).

The construct-a-map technique depends on the number of concepts and/or linking words provided by the instructor. Here the students are free to construct their maps. But the assessor should decide whether to ask the students to provide all the concepts or only a set of concepts in their maps. The scoring system for this technique is very complicated as each student draws a different map and the scoring is based on counting the number of nodes and linking lines to evaluate the accuracy of the map. If the students are asked to construct a map then students prepare it based on their prior knowledge. Since prior knowledge varies from student to student there will be a wide variation in the concept maps. Few students may select a set of concepts with which they are familiar and draw a map; others may include all the concepts in their map giving a chance to their luck (doing guess work). The results may mislead the instructor. There will be a wide variation in each student's map. This was observed when thirty graduate students were given twentyfive green building concepts on "Levelized Cost of Energy" to draw a concept map. Some students selected one to ten concepts from the list and others selected all the concepts even though they are not familiar with them. Some had difficulty drawing the map itself. Thus, construct-a-map procedure did not give the accurate output and the evaluation process is difficult. 
The fill-in-the map technique provides students with a concept map where either the concepts or the linking words are left out. The students are asked to fill the blanks in the map. The problem associated with this technique is, the structure of the map is predefined and it is difficult to judge whether the student's knowledge structure is becoming increasingly similar to that of the expert (Primo et al., 1998). It is difficult to understand the student's prior knowledge. The evaluation is not time taking but the results might not be accurate. Even if the students are not familiar with the concepts they may fill in the blanks provided in the map. Figure 3 is an example of a fill-in-the map. Both techniques have limitations associated with them. Table 1 shows the pros and cons of the two concept mapping techniques.

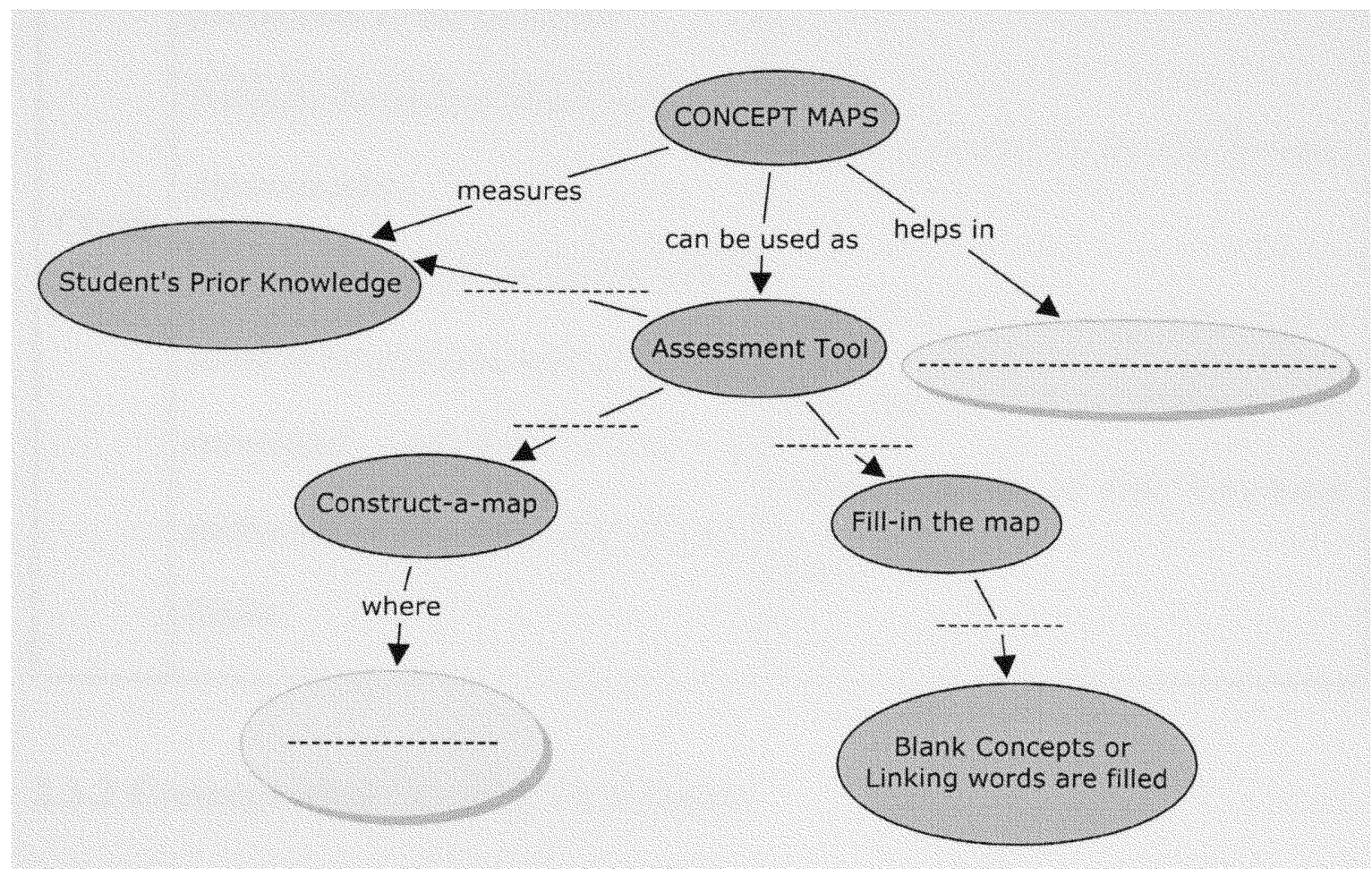

Figure 3: Fill-in-the map having two concepts and four linking words as blanks 
Table 1: Pros and Cons of the two mapping techniques

\begin{tabular}{|c|c|c|}
\hline \multirow{3}{*}{ PROS } & FILL-IN-THE MAP & CONSTRUCT-A-MAP \\
\hline & $\begin{array}{l}\text { Easy to score the map as the map is } \\
\text { pre-defined. }\end{array}$ & $\begin{array}{l}\text { Student is free to construct the map } \\
\text { selecting any number of concepts } \\
\text { from the list given by the instructor. }\end{array}$ \\
\hline & Students find it easy to answer. & $\begin{array}{l}\text { Has a wide scope to understand the } \\
\text { student's knowledge structure. }\end{array}$ \\
\hline \multirow{3}{*}{ CONS } & $\begin{array}{l}\text { Difficult to understand the student's } \\
\text { knowledge structure as the map is } \\
\text { pre-defined by the instructor. }\end{array}$ & $\begin{array}{l}\text { Time consuming for preparing the } \\
\text { map by the student. }\end{array}$ \\
\hline & $\begin{array}{l}\text { Restricts the student's knowledge } \\
\text { representation. }\end{array}$ & Time consuming for scoring the map. \\
\hline & $\begin{array}{l}\text { The assessor needs to decide which } \\
\text { terms to be provided among the ones } \\
\text { considered relevant within a } \\
\text { particular domain and topic (Primo, } \\
\text { 2004). }\end{array}$ & $\begin{array}{l}\text { Difficult to score the student's map as } \\
\text { each student has a different map } \\
\text { which is based on their knowledge } \\
\text { level. }\end{array}$ \\
\hline
\end{tabular}

\subsubsection{Concept Map Scoring Techniques}

The two main approaches for scoring concept maps are qualitative and quantitative methods. Qualitative scoring involves assessing the content validity and 
accuracy of the information presented in the concept map. Quantitative approach involves the counting of nodes or concepts, links, propositions and levels (Miller et al., 2007). As per Novak and Govin (1984) concept maps can be scored by assigning points to the valid propositions, levels of hierarchy, number of branchings, crosslinks and examples. The scoring technique is a very time consuming process.

There are problems associated with the assessment and scoring techniques of concept maps. Assessment tasks not only elicit but also influence students' responses. The characteristics of the assessment tasks may make students respond in ways that are not relevant, such as guessing the concepts and its relationships. It fails in tapping the knowledge structure of the student. The problem with the scoring system is that it cannot capture information about the quality of student's responses (Primo, 2004).

\subsection{LEARNING STYLES}

Apart from addressing the student's knowledge background it is important to note how they learn. Knowledge can be imparted easily if the concepts are customized to the student's learning style. Students perform better in environments and with approaches that complement their learning styles than in environments that do not support their learning styles (Dunn et al., 1989). Although the relationship between learning styles and academic performance is not very clear, students are likely to be prone to certain learning preferences, which ultimately impact their relative motivation and satisfaction in a learning environment (Bright et al., 2008). According to Keefe (1979) a learning style is defined as the "composite of characteristic cognitive, affective, and physiological factors 
that serve as relatively stable indicators of how a learner perceives, interacts with, and responds to the learning environment." Every individual has an inherent learning style. The way in which the students perceive, the medium through which knowledge is communicated, organization of knowledge, and the student's progress towards understanding it are important aspects to be focused on in order to learn about the student's learning style (Felder \& Silverman, 1988). It is the way in which a person absorbs and retains information and skills. It differs from person to person regardless of how that process is described (Sims \& Sims, 1995). As per Felder and Silverman learning styles of most engineering students and teaching styles of most engineering professors are incompatible in many ways.

\subsubsection{Importance of Learning Styles}

Many researchers have introduced different learning styles and theories. Few such researchers are Vygotsky, Dunn, Curry, David Kolb, Howard Gardner and Benjamin Bloom. There are 71 taxonomies of learning styles (Coeffield et al., 2004). Effective pedagogy must employ a multitude of modalities that addresses various learning styles and preferences. In particular, instructional materials presented in a variety of formats that are aligned to student preferences are more likely to engage and maintain student attention and be conductive to learning (Bright et al., 2008).

According to Sims and Sims (1995), there are three facts about the learning styles of the individuals. They are,

1. By the time we reach adulthood, each of us has developed our own methods of learning. That is, adult learners each have a unique and well-established style. 
2. Higher education instructors as well as trainers have developed methods of delivering materials, putting together sessions, and transforming content to the participants. That is, instructors and trainers also have a fairly well-established teaching or training style.

3. The more compatible the style of learning is with the style of instructing or training, the more likely it is that there will be a positive learning or teaching experience.

\subsubsection{Learning Style Models}

Coeffield et al. (2004) have conducted a detailed study on different learning style models. They identified five families which formed the basis for their analyses of different models. They are, constitutionally based learning styles and preferences, cognitive structure, stable personality type, 'flexibly stable' learning preferences and, learning approaches and strategies. They summarized 13 major models of learning styles. They are as follows:

1. Allison and Hayes' Cognitive Style Index (CSI).

2. Apter's Motivational Style Profile (MSP).

3. Dunn and Dunn's model and instruments of learning styles.

4. Entiwistle's Approaches and Study Skills Inventory fot students (ASSIST).

5. Gregorc's Style Delineator (GSD).

6. Herrmann's Brain Dominance instrument (HBDI).

7. Honey and Mumford's Learning Styles Questionnaire (LSQ). 
8. Jackson's Learning Styles Profiler (LSP).

9. Kolb's Learning Style Inventory (LSI).

10. Myers-Briggs Type Indicator (MBTI).

11. Riding's Cognitive Styles Analysis (CSA).

12. Sternberg's Thinking Style Inventory (TSI).

13. Vermunt's Inventory of Learning Styles (LSI).

\subsubsection{Learning Styles in Practice}

Among the different theories VAK (Visual, Auditory and Kinesthetic) model is a widely known theory. This model has been widely used in schools in the United States. This model is little similar to the Dunn's model. The Dunn's model stresses the importance of identifying and addressing individual differences in the learning processes (Griggs, 1991). The Dunn and Dunn (1978) model is a multidimensional model with reliable and valid instrumentation and a strong research base. The use of the Dunn and Dunn Learning Styles Model involves two main types of activities, one is identification of individual learning styles, and the other is the planning and implementation of instruction to accommodate individual students' learning style strengths.

The VARK (Visual, Auditory, Reading and Kinesthetic) learning style model can be considered as the advanced version of VAK (Visual, Auditory and Kinesthetic) model. VARK model was introduced by Neil Fleming (2001). His experience of working with students and teachers (9000 classes) for several years made him come up with the VARK learning style model. 
Neil Fleming's (2006) ideas about preferred learning modes include the following:

- Modal preferences influence individuals' behaviors, including learning.

- Modal preferences are not fixed, but they are stable in the medium term.

- Both students and teachers can reliably identify and provide examples of their use of modality preferences in learning.

- Preferences can be matched with strategies for learning. There are learning strategies that are better aligned to some modes than others. Using your weakest preferences for learning is not helpful; nor is using other students' preferences.

- Information that is accessed using strategies that are aligned with a student's modality preferences is more likely to be understood and be motivating.

- The use of learning strategies that are aligned with a modality preference is also likely to lead to persistence learning tasks, a deeper approach to learning, active and effective metacognition.

- Knowledge of, and acting on, one's modal preferences is an important condition for improving one's learning.

Researchers in the field of education largely agree that people prefer learning new information in one of the three primary ways: seeing, hearing and experiencing (Lovelace, 2005). They are called as the Visual, Auditory and Kinesthetic styles abbreviated as VAK. Visual learners learn by seeing, auditory learners learn by listening and kinesthetic learners learn by doing. Information for visual learners can be presented in the form of maps, spider diagrams, charts, graphs, flow charts, labeled diagrams, and all the symbolic arrows, circles, hierarchies and other devices that instructors use to represent what could 
have been presented in words. It can include designs, patterns, shapes and the different formats that are used to highlight and convey information (Fleming, 2001). Visual learners visualize concepts of theory and content received through patterns or pictures in their mind. Prior knowledge for these students can be activated by providing them with the content that ties to the previous concepts. This allows mental images to connect and provides reinforcement for learning new concepts (Lucas, 2003). Auditory learners are good at listening to lectures, tapes and participating in discussions. The needs for these students can be met by getting them involved in verbal exchange, instructor-led discussions, music, debates, panel discussions, role plays, interactive CD-ROM, reading text aloud, used of tape recorders, or demonstrations involving verbal explanations (Lucas, 2003). Kinesthetic learners learn by hands-on-experience. This modality refers to the "perceptual preference related to the use of experience and practice (simulated or real)." People who prefer this mode are connected to reality, "either through concrete personal experiences, examples, practice or simulation". It includes demonstrations, simulations, videos and movies of "real" things, as well as case studies, practice and applications (Fleming, 2001). Interactive sessions, making models and experiencing things (sense of touch) are some examples of the ways in which a kinesthetic student learns. Multimodal learners are those who use all the modes of learning. Those who prefer many modes almost equally are of two types. There are those who are context specific who choose a single mode to suit the occasion or situation. There are others who are not satisfied until they have had input (or output) in all of their preferred modes. They take longer to gather information from each mode and, as a result, they often have a deeper and broader understanding (Fleming, 2001). 
Some critiques of learning style modals say that "Knowing one's learning style does not improve learning." According to Neil Fleming (2006), "Knowing one's learning style can be beneficial if learners take the next step, and consider how and when they learn, as part of a reflective, metacognitive process, with action to follow. You don't fully understand how you learn with a learning style inventory alone. What happens afterwards has the potential to make a difference."

\subsubsection{Implementation of Learning Styles}

Many studies have found that the general population is approximately $65 \%$ visual, $20 \%$ auditory and 15\% kinesthetic learners (www.animators.com). A VARK (Visual, Auditory, Reading, Kinesthetic) questionnaire prepared by Neil Fleming and Colleen Mills (1992) helps in understanding an individual's learning style and in measuring direct instructional attributes. Questions are based on revealed choices in applying learning to situations. It has general questions about how individuals behave, experience and do things in their daily life. Based on the results of the questionnaire one can judge the predominant learning style of students. Most individuals may have more than one learning style but there will be one predominant learning style. If an individual uses more than one learning style then the individual has multimodal style of learning (https://tt.qut.edu.au/it/itb116/gen/static/vak/Index.htm). The Fleming-Mills learning style inventory is related to several other learning style instruments such as Kolb's Learning Style Inventory (LSI) and Myers-Briggs type indicator (Nefstead,1998). 
Felder and Silverman's (1988) research on learning and teaching styles in engineering education introduces the index of learning styles. They are Sensing/Intuiting, Visual/Verbal, Active/Reflective, and Sequential/Global dimensions. Sensors remember and understand information best if they can see how it connects to the real world. They like facts, data, and experimentation. Intuitors prefer principles and theories. Visual learners remember best what they see. Verbal learners get more out of words - written and spoken explanation. In most colleges classes very little visual information is presented: students mainly listen to lectures and read material written on chalkboards and in textbooks and handouts. Most people are visual learners, which mean that most students do not get nearly as much as they would if more visual presentations were used in class. Good learners are capable of processing information presented either visually or verbally. Sequential learners tend to gain understanding in linear steps, with each step following logically from the previous one. Global learners tend to learn in large jumps, absorbing material almost randomly without seeing connections, and then suddenly "getting it." Many or most engineering students are visual, sensing, inductive, and active, and some of the most creative students are global; most engineering education is auditory, abstract (intuitive), deductive, passive, and sequential. These mismatches lead to poor student performance, professorial frustration, and a loss to society of many potentially excellent engineers (Felder \& Silverman, 1988).

Among all the learning style models described above, VAK/VARK model has proved to have more similarities with other models and this model can be implemented in order to understand the learning styles of students. As per Corbett and Smith (1984), 
"The purpose of learning style analysis is to identify student strategies for learning and to wed them with instructional or training materials, experiences, instruction, and methods that foster a high rate of return - efficient, lasting achievement within a logical amount of time."

The VARK learning style model was used as a measure of individual student's cognitive style in order to predict student success with remote labs in the engineering education by Nickerson et al. (2005). This specific instrument was used by a team as it measures student preferences for specific modes of communication, including visual, auditory, textual, and kinesthetic modes and because the possibility of students being kinesthetically-oriented seems relevant to predicting student success with remote labs. Total VARK scores did predict higher ratings of effectiveness for the remote labs, and also predicted a lower rating of the importance of physical presence in the lab. This suggested that remote labs might be especially appropriate for students possessing a highly visual or highly flexible learning style.

Clemons (Clemons, 2004) who is an associate professor at Colorado State University designed a distance education instructional design program for interior designing students based on visual and kinesthetic learning styles. Two visual/kinesthetic courses were designed out of which one is on interior design and the other on color. The courses were designed by her with three basic thoughts. They are, "how can the information be delivered to different modalities?", "how can assessment of students 
learning be obtained keeping multiple modalities in mind?", "how can technology enrich the learning environment?"

The techniques used to teach the content of interior design and color to visual and kinesthetic learners are as follows:

- For the visual modality - Internet Field Trips, Internet Scavenger Hunt, Discovery and Identification, Response and Analysis were implemented. Internet field trips were implemented to encourage learning through observation. Students visit websites of famous architects and designers to listen audio clips of design concepts and philosophies. They visited Frank Gehry's website to observe form and shape as used in the design field. They also visited national and international websites concerning color and color theorists. Internet scavenger hunt was implemented to encourage learning through discovery and exploration. Questions were posed on the assignment sheet in a format that necessitates students search and locate critical information about the topic. They were encouraged to not only discover, but explore the topic themselves. Discovery and identification were implemented to assess accurate identification of information covered. Response and analysis were implemented to encourage analysis of a professional topic.

- For the kinesthetic modality - Model Building, Color Mood Boards and Concept Boards were implemented. Model building was implemented to encourage learning through creativity and construction. Color mood boards were implemented to encourage learning through cultural and symbolic color 
application. Concept boards were implemented to encourage learning through visual depiction and communication of design concepts. PowerPoint presentations of student work were offered for all kinesthetic assignments to help visual learners understand the scope of the project.

The students who took theses courses were from different disciplinary backgrounds. The response of the whole session was very good and students remarked on the enjoyment of the visual and kinesthetically-driven assignment. Thus, it turned out to be a good mode of communicating knowledge.

\subsection{SUMMARY}

The student collaboration in the AEC domain, influence of prior knowledge, concept mapping and learning styles are reviewed in this chapter.

Prior knowledge is an important factor to be considered as it influences how students learn new concepts. The concept presenting tool called the concept map is studied. The different aspects of it, its assessment and scoring systems are discussed. The discussion also had different types of learning style theories. The different learning styles in practice and its implementation were mentioned. All of them were studied and the one (VAK learning style) which seemed appropriate for this study was selected in order to conduct the experiment. 


\section{CHAPTER 3}

\section{RESEARCH PROCESS}

\subsection{INTRODUCTION}

The research is aimed at answering the following question: Does addressing and supporting students' prior knowledge and learning style help in improving concept learning?

In order to perform the study, a test was designed and conducted on a group of graduate students in construction management at Florida International University. Forty graduate students taking BCN 5728 (Principles of Construction Scheduling) course were tested. The students in the class are from different undergraduate disciplines (see Figure 4), including architecture (12 students), civil (11 students), mechanical (2 students), construction ( 3 students) and other (business management, law, psychology, biology and chemistry - 12 students) undergraduate degrees. There are more students from backgrounds which are not related to construction management (Figure 4). Collaboration in this diverse environment is slightly time taking and difficult as their prior knowledge influences the current concept learning process. Since their undergraduate degrees vary, each student may have a different perception of the green building concepts. All these aspects are addressed when the test is designed.

The research is conducted in four different stages (Table 2). The first stage helps in understanding the prior knowledge of the students. The second stage is to understand 
the learning style of each student. The third stage is designed based on the first two stages. Here, the material is designed according to their learning styles and prior knowledge. The fourth stage evaluates the improvement of concept learning from the first stage through the final stage and tests the hypothesis.

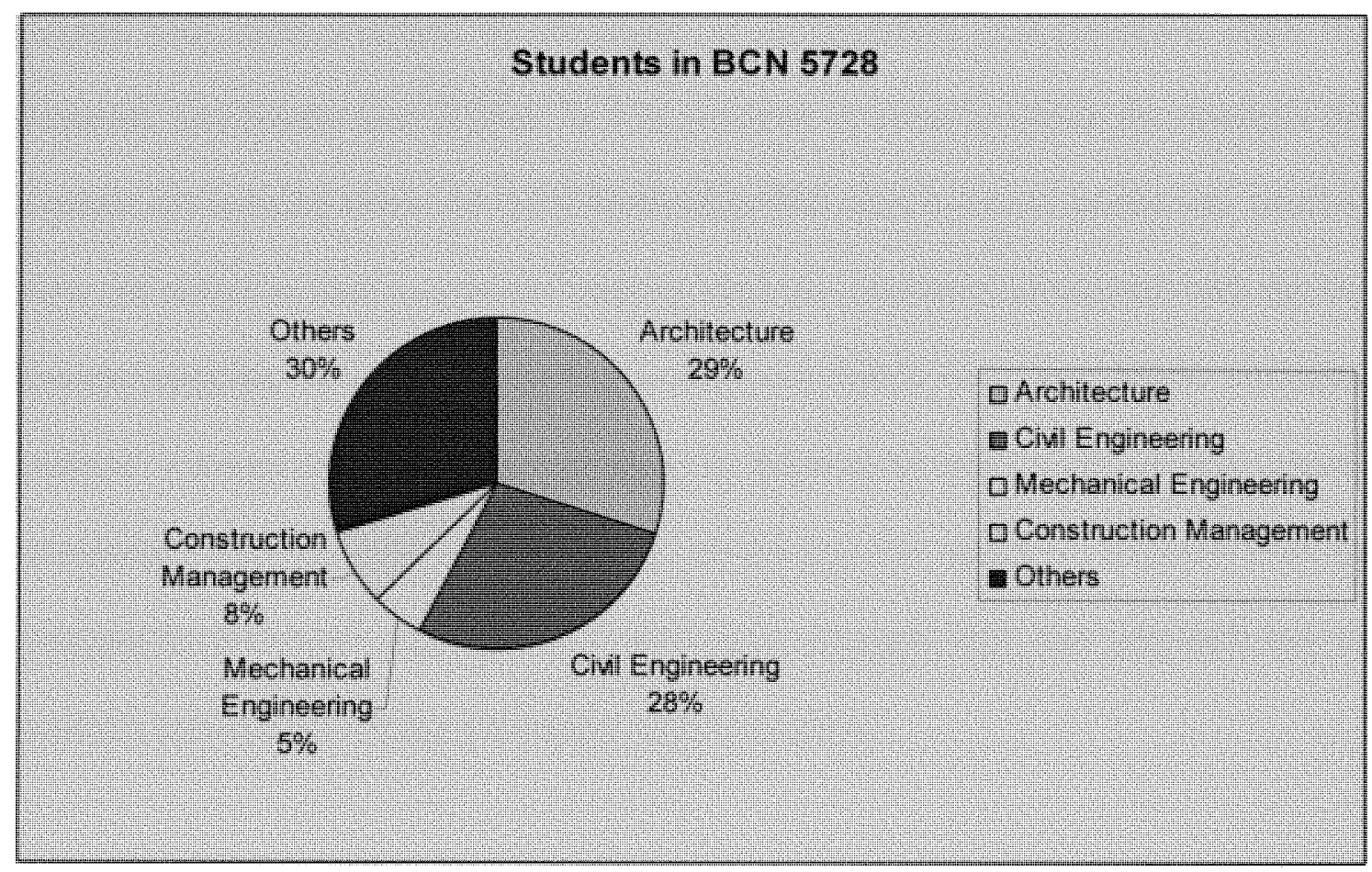

Figure 4: Percentage of students from different undergraduate degrees

Table 2: Stages of Research

\begin{tabular}{|c|c|}
\hline Stage I & Prior knowledge test \\
\hline Stage II & Understanding learning styles \\
\hline Stage III & style \\
\hline Stage IV & Final evaluation of concept learning \\
\hline
\end{tabular}


The test was performed by selecting green building related concepts "Structural Insulated Panels (SIPs)." Structural insulated panels are energy efficient and are used for exterior building envelops. The whole study revolves around different concepts (architectural, construction, structural and mechanical) related to SIPs. Initially an expert concept map (map prepared by an expert or an instructor of a particular field) was prepared. The expert map (Figure 5) was prepared in order to check the concepts that students are missing when the prior knowledge and final tests are conducted. Students were not asked to draw a concept map as there are problems associated with the two concept mapping techniques (construct-a-map and fill-in the map). While evaluating students' answers the expert concept map can be used in order to check their concept knowledge. The tests were analyzed by comparing the students' answers with the concepts in the expert concept map. An expert concept map was prepared and the student's concept knowledge was tested with it as a base.

\subsection{STAGE I - PRIOR KNOWLEDGE TEST}

Since the students are from different undergraduate degrees it is important to check their prior knowledge of concepts on green building (structural insulated panels). This helps the instructor in understanding the knowledge that the students bear. SIPs have concepts, which are related to architecture, structural, construction and mechanical fields. Concepts from each discipline are color coded in the expert concept map. Color coding is done as the instructor can easily gauge the student's level of concept knowledge by seeing the missing colored concept. The evaluation of the student's knowledge about the other disciples becomes easy if the concepts are color coded according to disciplines. For 
example, if the student's background is mechanical (grey color in the Figure 5), the student might not have the knowledge of concepts from architecture discipline (blue color in the Figure 5). Concept maps can be used as a scale for measuring knowledge that the students have in a multidisciplinary setting.

A multiple choice test was formulated based on some very basic concepts from the expert's concept map. This test was given to the students in order to check their existing knowledge of green building concepts (Appendix 1). The purpose of including these questions in the prior knowledge test is to identify the conceptual knowledge of students from varied backgrounds (undergraduate education). The first question in the test was focused directly on the green building. The characteristics of a green building were asked. This is to understand if the student is aware of a green building. Later, questions were focused on some green building concepts (questions 3 and 4 in appendix 1) and structural insulated panels. Sometimes if the students have no previous knowledge on a particular concept they may tend to answer something which they might feel is correct. This will mislead the instructor. So, each question was provided with an option "No idea" in order to get the exact answer. Students were informed to mark the option "No idea" if they are not familiar with the concepts. Evaluation of the prior knowledge test will help in identifying the student's level of knowledge on the concepts of SIPs. 


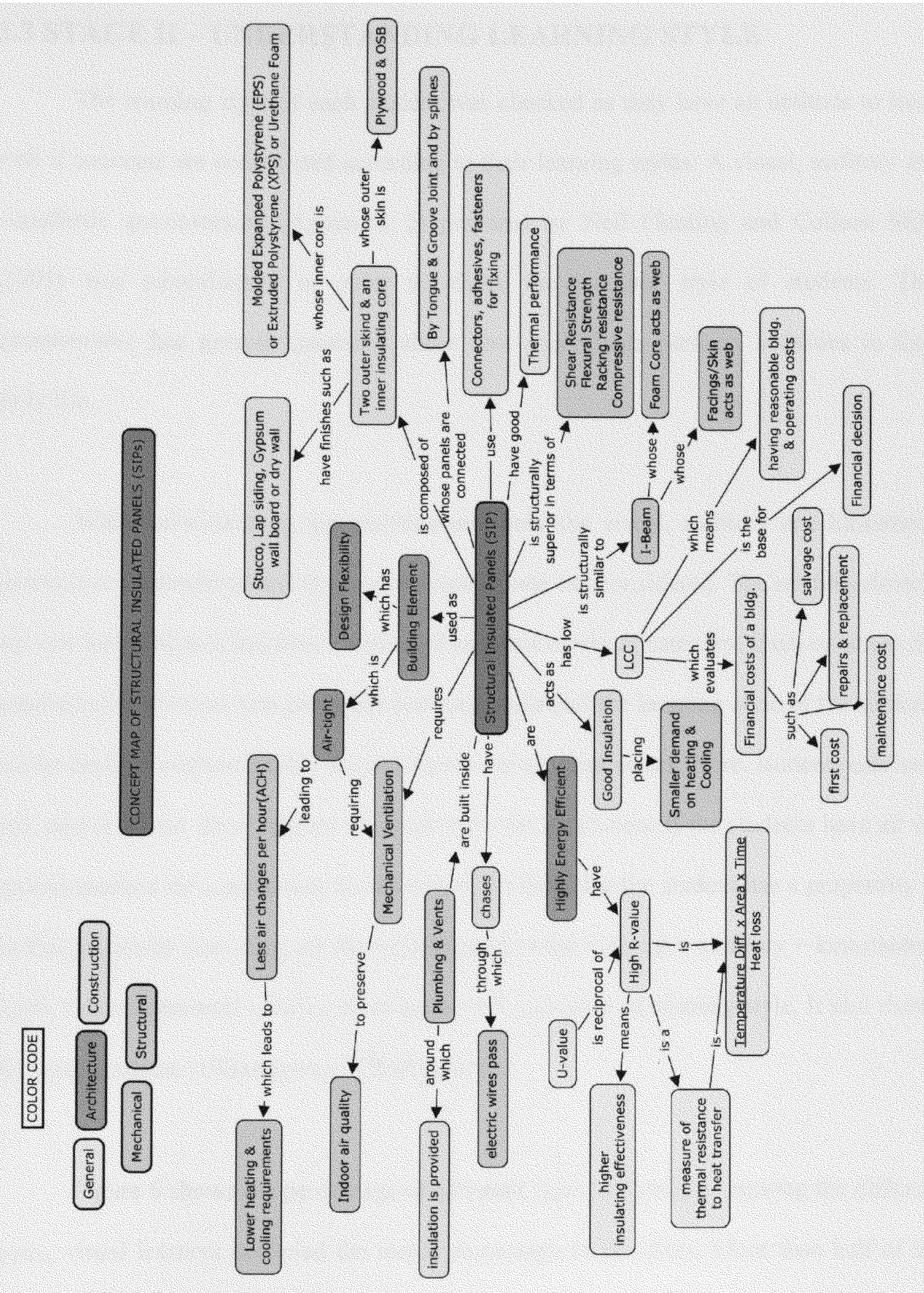

Figure 5: Expert Concept Map with the different disciplines color coded. 


\subsection{STAGE II - UNDERSTANDING LEARNING STYLE}

The learning style of each student was checked as they have an aptitude to learn well if concepts are constructed according to their learning styles. A visual, auditory and kinesthetic questionnaire (Appendix 2) prepared by Neil Fleming and Colleen Mills (2001) was administered in order to check the learning style of students. This questionnaire has general questions about how individuals perform activities in their daily life.

While administering the questionnaire only the visual, auditory and kinesthetic elements are considered and the reading/writing was not considered. The reading element was not included as it has been considered as a part of visual category. Each option in the questionnaire portrays one particular learning mode and the learning style of the students can be easily recognized from the answers to the questionnaires. Here, students can have one, two or all the three options as the answers for a question. If the students have all the options marked for a particular question then it shows that the student has a propensity to do that particular task using all the modes (multimodal $=$ visual + auditory + kinesthetic $)$. Table 3 shows the total number of students with each type of learning style. It also shows the undergraduate (UG) degrees of the students.

Figure 6 shows the percentage of different types of learners. Among the different types, visual learners occupied the major percentage of the class. More than half of the class $(62 \%)$ is visual learners. The next predominant style is the multimodal learners $(13 \%)$ who had more than two learning modes. The immediate style next to the 
multimodal is the kinesthetic (12\%). There are no auditory students in the class. Visual Auditory (VA) type learners are 10\% and Auditory - Kinesthetic (AK) are of 3\%.

Table 3: Students based on their learning style modality

(Visual, Auditory, Kinesthetic, Visual and Auditory - VA, Auditory and Kinesthetic AK, Visual and Kinesthetic - VK, Multimodal)

\begin{tabular}{|c|c|c|c|c|c|c|c|}
\hline$\underbrace{\text { Learner Type }}_{\perp \text { UG Degree }} \rightarrow$ & $\begin{array}{c}\text { Visual } \\
(\mathrm{V}) \\
\end{array}$ & $\begin{array}{c}\text { Auditory } \\
\text { (A) }\end{array}$ & $\begin{array}{c}\text { Kinesthetic } \\
(\mathrm{K})\end{array}$ & VA & $\mathrm{AK}$ & VK & Multimodal \\
\hline Architecture & 7 & 0 & 2 & 2 & 1 & 0 & 0 \\
\hline Civil & 8 & 0 & 1 & 1 & 0 & 0 & 1 \\
\hline Mechanical & 1 & 0 & 0 & & 0 & 0 & 1 \\
\hline $\begin{array}{l}\text { Construction } \\
\text { Management }\end{array}$ & 2 & 0 & 0 & 1 & 0 & 0 & 0 \\
\hline Others & 7 & 0 & 2 & 0 & 0 & 0 & 3 \\
\hline TOTAL & 25 & 0 & 5 & 4 & 1 & 0 & 5 \\
\hline
\end{tabular}

Figure 6: Pie Chart showing the different types of learners in BCN 5728 class.

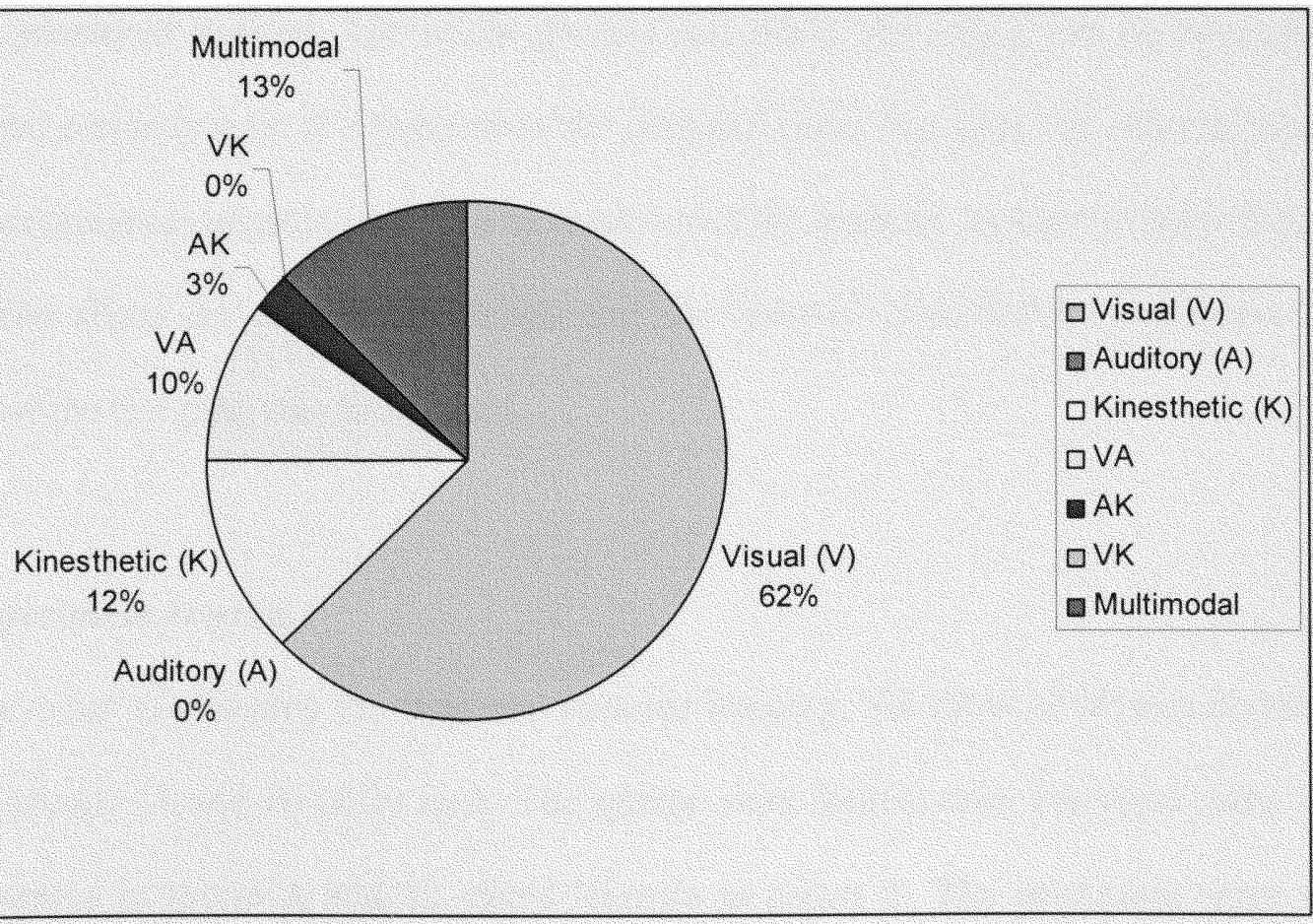




\subsection{STAGE III - CONCEPT PRESENTATIONS BASED ON LEARNING STYLES}

The questionnaire helped in understanding the types of learners. After knowing the percentage of students with each learning style, material is presented to them accordingly. Based on the students' prior knowledge each one of them was given a customized plan which gives them the concepts they need to focus on. For example, if it is observed (from the prior knowledge test response) that a student has good knowledge of SIPs, then that student is given guidance such that he or she learns only the missing concepts in the first test. The material in stage III is tailored to the students' prior knowledge of SIPs. Students having zero prior knowledge on SIPs are guided to learn each and every concept in a planned manner. This guidance is given to students in both groups along with the materials.

Students were then given twenty minutes to go through and understand all the concepts presented to them. The whole process was timed. An output can be compared and gauged correctly only if it happens in the allocated time. The speed of understanding and the accurateness of perception can be measured if the learning process is timed. Stage III explains about the experiment design and the material development procedure. It shows how the test plan was formulated.

\subsubsection{Experiment Design}

In order to compare the students' concept learning, the class of 40 was divided into two groups (A and B) of 20 each. The groups were formed such that there were 13 visual learners in group A and 12 visual learners in group B. The remaining types of 
learners were divided among the two groups. Table 4 shows the composition of students in each group. Visual learners in group A are given visual materials and visual learners in group B are given non visual (conventional) materials. Students who had kinesthetic and multimodal learning styles are also divided among the two groups. The students are divided such that there are equal numbers of visual and other types.

The test was conducted such that one group of visual learners is given visual materials and the other group of visual learners is given non visual (conventional) materials. This is to determine whether visual materials help visual learners or not. The differences in the final score and the improvement of concept learning from the prior knowledge for visual learners in both groups are compared. Similarly, other types (kinesthetic and multimodal) of learners are made to learn visual and conventional materials and the differences in learning are observed. A comparison between two groups can be done when the type of learners in both are equally distributed.

Table 4: Group A and Group B division

\begin{tabular}{|c|c|c|}
\hline Group Names & GROUP A & GROUP B \\
\hline Visual Learners & 13 & 12 \\
\hline $\begin{array}{c}\text { Other types } \\
\text { (Kinesthetic and Multimodal) }\end{array}$ & 7 & 8 \\
\hline TOTAL & 20 & 20 \\
\hline
\end{tabular}




\subsubsection{Material Development}

All concepts of SIPs are presented with the help of figures, images, graphs and concept maps for group A students. For example, the figures helped in showing the structural composition of SIPs (Figure 7). Some part of the materials are visually represented and the remaining part of the materials were explained with the help of concept maps which is a graphical tool for representing concepts. Figure 7 shows a sample of how concepts are presented to the students by using a very simple concept map and a supporting image.
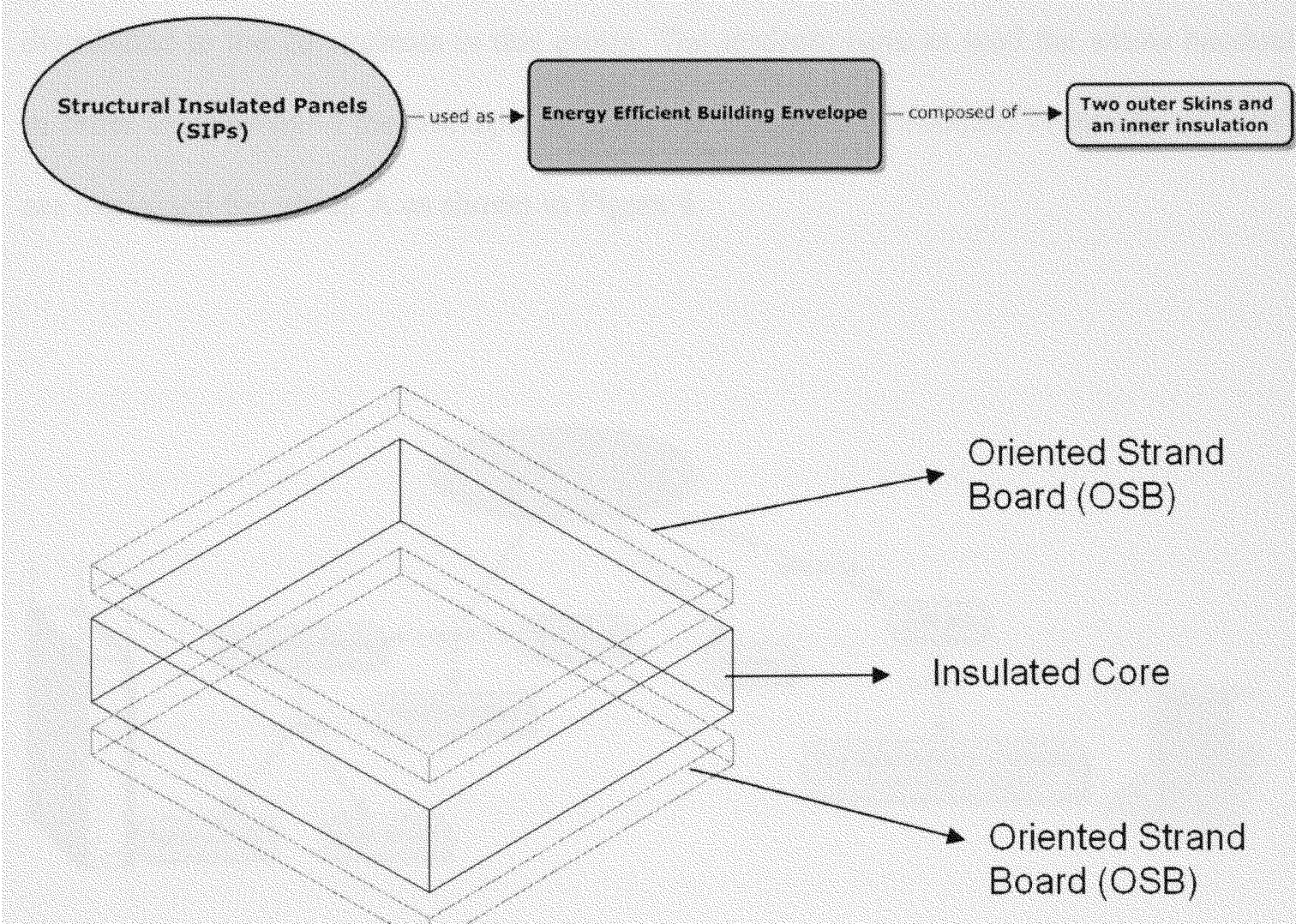

Figure 7: Structural composition of SIPs 
The major and important part of the materials is initially explained with the concept maps. Later, each of them was explained with an image/figure. Since concept maps help in depicting the concepts with the relations among them, it makes a student easy to understand how the different concepts are related to each other apart from the meaning of each concept. The information on SIPs was divided into different categories (general, structural, design, construction and mechanical aspects) focusing on the concepts coming from different disciplines involved in it. The material was prepared in Microsoft FrontPage and presented to the students. Group B was presented with the same information put in the conventional format. Handouts having information on SIPs were distributed to the 20 students in this group. The students have to read the whole handout in order to understand the concepts of SIPs. For example, "Structural Properties of SIPs" are explained for group A as shown in Figure 8.

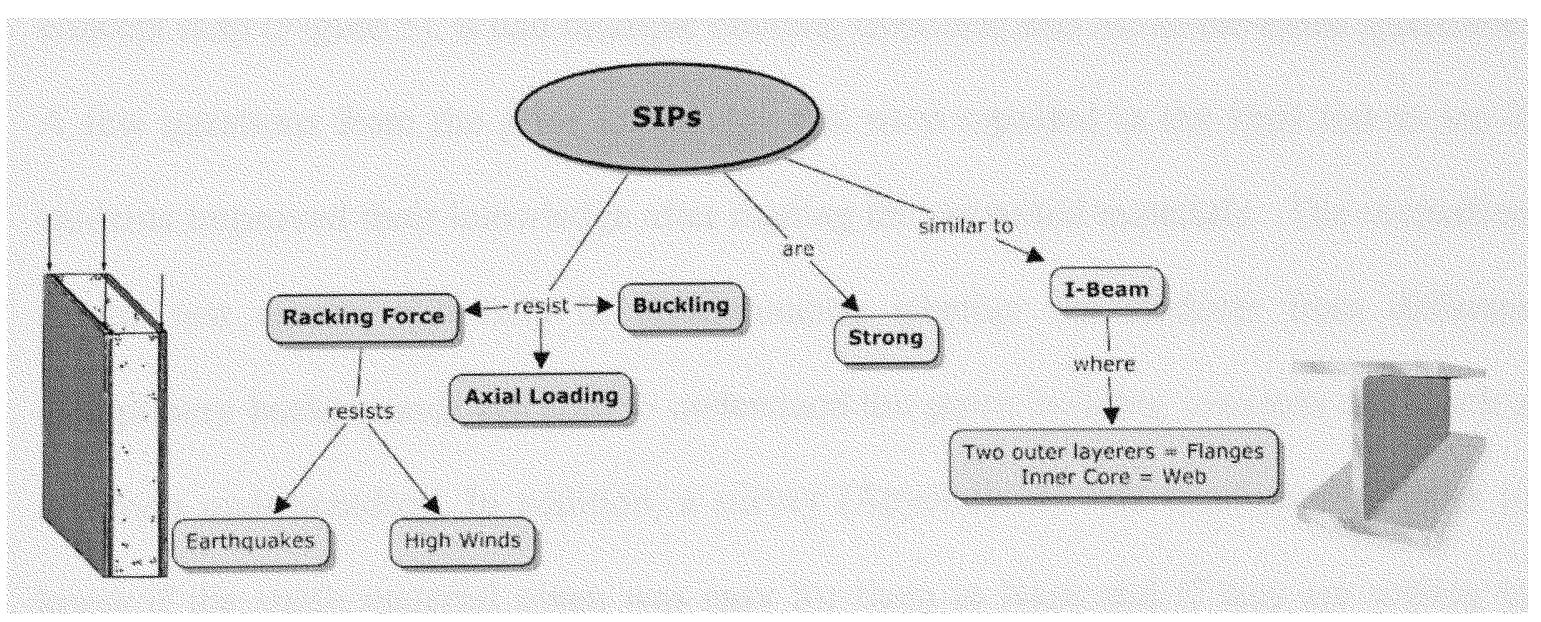

Figure 8 - Presentation of concepts of the "Structural Properties of SIPs" for Group A 
Though the information given to both the groups was the same, the presentation and depiction of concepts was completely different. For Group A, all the concepts were made more visual. Some concepts which cannot be depicted with the concept maps or images were explained with text supported by a relevant figure.

\subsection{STAGE IV - FINAL EVALUATION OF CONCEPT}

\section{DEVELOPMENT}

A final test (Appendix 3) was conducted in order to determine the development in the student concept learning process when prior knowledge and learning styles are addressed. While testing, it was observed that group B students took longer time to answer the questions than group A. The test was prepared with the help of the master concept map. In the prior knowledge test (Stage I) only basic concepts were questioned. The final test included questions based on all the remaining concepts in the expert concept map (Figure 5). It had multiple choices, true/false and fill-in-the-blank questions. A few questions from the prior knowledge test were repeated in the final test to see if students improved their knowledge after reading the presented materials. The evaluation of the test results will help in understanding whether the students from different disciplinary backgrounds are able to understand the green building concepts and reach a common understanding. In addition, a survey (Appendix 4) was conducted in order to know if the study material given was easy for them to learn and if they are willing to learn the material customized to their preferred learning styles. 


\subsection{SUMMARY}

In this chapter, the process of this study was discussed. The four different stages of the test are explained and the factors considered in each stage are detailed. The procedure in which learning materials was developed and presented is also explained. The survey which was conducted at the end of the experiment proved that majority of the students in the class were willing to learn the concepts visually (graphs, images, figures and concept maps) and by participating in group discussions rather than conventional lecture format. 


\section{CHAPTER 4}

\section{DATA ANALYSIS}

\subsection{INTRODUCTION}

A statistical analysis was done in order to analyze the performance of the test.

There are many statistical techniques used to compare groups. They are one-sample z-test, independent-samples t-test, paired-samples t-test, one-way analysis of variance, two-way analysis of variance, MANOVA, ANCOVA etcetera. Among the mentioned, the tests that compare only two groups are one-sample z-test, one-sample t-test, independent groups t-test and repeated measures t-test. The statistical procedure that is used here is the student's t-test. T-test is the most appropriate among all because it is used when the comparison is between two independent sample means which are made up of different groups of individuals. There are three different types of t-tests. They are one-sample t-test, two-independent samples t-test, and paired-samples (matched-cases) t-test. Since the comparison here is between two unpaired groups, independent sample t-test was conducted. In an independent-samples design, there is no relationship between people or objects in the two groups.

\subsection{STUDENT'S T-TEST}

The output from the t-test procedure is shown in two tables (Tables 5 and 6).

Table 5 shows the group statistics and Table 6 shows an independent samples test. The interpretation of the output is explained below. 


\subsubsection{Interpretation of output from independent-samples t-test:}

\section{Group Statistics:}

Group statistics table shows the groups (A and B) which are considered for the comparison, their sample sizes $(\mathrm{N})$, their sample means, their standard deviations, and their standard error mean. This can be observed in Table 5 .

Table 5: Descriptive statistics concerning the variables

\begin{tabular}{|l|c|c|c|c|c|}
\hline & Group & $\mathrm{N}$ & Mean & $\begin{array}{c}\text { Std. } \\
\text { Deviation }\end{array}$ & $\begin{array}{c}\text { Std. Error } \\
\text { Mean }\end{array}$ \\
\hline \multirow{2}{*}{ Difference_Score } & $\mathrm{A}$ & 11 & 54.9073 & 21.76504 & 6.56241 \\
\cline { 2 - 6 } & $\mathrm{B}$ & 8 & 41.5363 & $14 / 12447$ & 4.99375 \\
\hline
\end{tabular}

\section{Independent samples test:}

The first section of the independent samples test (see Table 6) output box gives the results of Levene's test for equality of variances. This tests whether the variance (variation) of scores for the two groups (Group A and B) is the same (Pallant, 2001). In the Levene's test a null hypothesis that two comparing samples have the same variance is assumed. If the significance level (Sig.) or p-value is larger than 0.05 (e.g., 0.07, 0.10), assuming $95 \%$ confidence interval, the null hypothesis will be accepted and the first line in the Table 6, which refers to Equal variances assumed should be used. If the significance level of Levene's test is less than or equal to 0.05 (e.g., 0.01, 0.001), the null hypothesis will be rejected and the alternate hypothesis will be accepted. In this case the second line of the t-test table, Equal variances not assumed should be considered. 
Table 6: Independent samples test

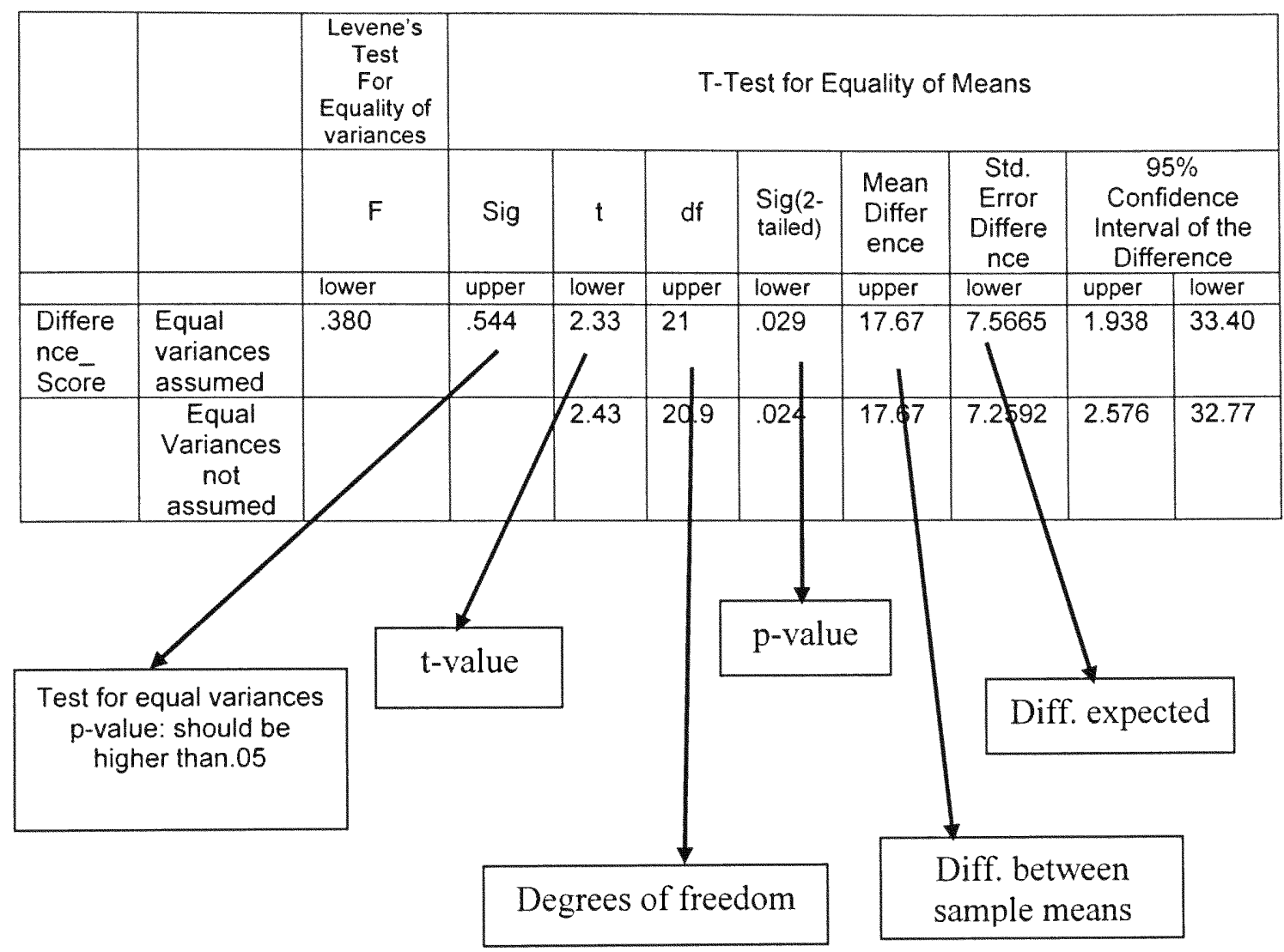

To find out if there is a significant difference in the mean between the two groups ( $\mathrm{A}$ and B) column labeled Sig. (2-tailed) should be referred (see Table 6). This appears under the section labeled t-test for equality of means. Two values, one for equal variance and the other for unequal variance will be given. Choose the value according to the Levene's test which is explained in the previous paragraph. If the value in the Sig. (2-tailed) column is equal or less than .05 (e.g., .03, .01, .001), assuming 95\% confidence interval $(\alpha=0.05)$ then there is a significant difference in the mean scores on the dependent variable for 
each of the two groups. If the value is above .05 (e.g., .06, .10) there is no significant difference between the two groups (Pallant, 2001).

Confidence interval range is used to interpret significance of the association between the means. If the range does not include zero, the mean difference is significantly different from zero. That is, the two means are significantly different from each other. If the range include zero, the two means are not significantly different from each other.

\subsubsection{Calculating the effect size for independent-samples t-test:}

Effect size statistics provide an indication of the magnitude of the differences between the groups (not just whether the difference could have occurred by chance). There are a number of different effect size statistics, the most commonly used is eta squared. Eta squared can range from 0 to 1 and represents the proportion of variance in the dependent variable that is explained by the independent (group) variable. It can be calculated using the information provided in the output. The procedure for calculating eta squared is provided below (Pallant, 2001).

The formula for eta squared is as follows:

Eta squared $\left(\eta^{2}\right)=\frac{t^{2}}{t^{2}+(N 1+N 2-2)}$

The guidelines (Cohen, 1988) for interpreting this value are: 0.01 or less is small effect, 0.06 or less is moderate effect, and around 0.14 is large effect. 


\subsection{ANALYSES OF THE TEST RESULTS}

The test was conducted in stages as discussed in chapter 3 . There are 40 students in the prior knowledge test but the number of students reduced to 23 when it came to the final test. The test was conducted with 13 students in Group A and 10 students in group B. The data is analyzed from three different perspectives (Test 1, Test 2 and Test $3-$ Appendix 5 and 6). The idea behind doing the analyses with three different criteria is to answer the research questions: Is there a significant difference in the mean scores for Group A and Group B when the learning styles and prior knowledge are addressed? And if there is a difference which group performed well?

In order to test the hypothesis, the evaluation was planned in three different methods. In the first evaluation process (Test 1), the difference in the scores of the prior knowledge test and the final test are summarized. By this one can understand which group had more improvement in their concept learning when prior knowledge is addressed. The second evaluation process (Test 2) focuses on the material presented to both the groups. It will answer questions such as - "What is the score when some part of the material presented to them is similar in both cases?" and "What is the score when some part of the material presented to them is completely different in both cases?" This is to observe how both groups performed when the medium and method of material presentation is different. The third evaluation process (Test 3) focuses on specific questions given in the final test. Some study materials are bound to be presented either in text or through images irrespective of the group or type of learners. In such cases the variation in the scores for both the groups is observed. 


\subsection{1 - T-Test Analyses for Test 1}

This test compares the scores of the students' concept learning from the prior knowledge test through the final test (from Stage I to Stage IV) for both the groups (while addressing the learning styles).

Initially the prior knowledge test for both the groups was scored. Later after going through the whole process the final test was also scored. Test 1 analyzes the improvement of scores from the prior knowledge stage to the final stage. The difference of both the scores (final score and prior knowledge score) was considered and the mean was calculated in order to see the improvement of both the groups. That is, improvement in concept learning is equal to the difference between the final test score and prior knowledge test score (Figure 9).



Figure 9: Scores compared in group A and group B 
The mean of this value can be seen in the Table 7 which has the group statistics.

The mean score of group A with 13 students is 55.59 and the mean score of group B with 10 students is 37.92 .

Table 7: Group statistics for test 1

\begin{tabular}{|ll|r|r|r|r|}
\hline & Group & N & Mean & Std. Deviation & $\begin{array}{c}\text { Std. Error } \\
\text { Mean }\end{array}$ \\
\hline Difference_Score & 1 Group A & 13 & 55.5954 & 20.10894 & 5.57722 \\
& 2 Group B & 10 & 37.9210 & 14.69410 & 4.64668 \\
\hline
\end{tabular}

The descriptive statistics for group A and group B shows that the mean of group A is more than that of group B. That is, the improvement of scores from the prior knowledge test through the final test in group A is greater than the improvement in Group B.

Table 8 is the data from independent-samples t-test showing whether there is a statistically significant difference in the mean score for the two groups.

Table 8: Independent samples test for test 1

\begin{tabular}{|c|c|c|c|c|c|c|c|c|c|c|}
\hline & & \multicolumn{2}{|c|}{$\begin{array}{l}\text { Levene's Test } \\
\text { for Equality of } \\
\text { Variances }\end{array}$} & \multicolumn{7}{|c|}{ t-test for Equality of Means } \\
\hline & & \multirow{2}{*}{$\begin{array}{l}F \\
\text { Lower } \\
\end{array}$} & \multirow{2}{*}{$\begin{array}{l}\text { Sig. } \\
\text { Upper }\end{array}$} & \multirow{2}{*}{ tower } & \multirow{2}{*}{$\begin{array}{c}\text { df } \\
\text { Upper }\end{array}$} & \multirow{2}{*}{$\begin{array}{l}\begin{array}{l}\text { Sig. (2- } \\
\text { tailed) }\end{array} \\
\text { Lower } \\
\end{array}$} & \multirow{2}{*}{$\begin{array}{l}\text { Mean } \\
\text { Differ- } \\
\text { ence }\end{array}$} & \multirow{2}{*}{$\begin{array}{l}\text { Std. } \\
\text { Error } \\
\text { Differ- } \\
\text { ence } \\
\\
\text { Lower }\end{array}$} & \multicolumn{2}{|c|}{$\begin{array}{l}95 \% \text { Confidence } \\
\text { Interval of the } \\
\text { Difference }\end{array}$} \\
\hline & & & & & & & & & Upper & Lower \\
\hline $\begin{array}{l}\text { Difference } \\
\text { _Score }\end{array}$ & $\begin{array}{l}\text { Equal } \\
\text { variances } \\
\text { assumed } \\
\text { Equal } \\
\text { variances } \\
\text { not } \\
\text { assumed }\end{array}$ & .380 & .544 & 2.435 & 20.97 & .029 & $\begin{array}{r}17.67 \\
4\end{array}$ & $\begin{array}{r}7.566 \\
5\end{array}$ & 1.9388 & 32.772 \\
\hline
\end{tabular}

- The Sig. value ( $p$-value) for Levene's test is 0.544 . So, variances are equal. 
- The Sig. value (p-value) for t-test is 0.029 . So, there is statistically significant difference in Difference_score for group A \& B. Group A has statistically higher mean score on Difference_score (Difference_score means the difference between the final test score and prior knowledge test score).

- The $95 \%$ confidence interval ranges from 1.9388 to 33.409 . So, the two means are significantly different from each other.

- Calculating the effect size for independent-samples t-test:

From the independent sample table, $\mathrm{t}=2.336$

$$
\text { Eta squared } \begin{aligned}
\left(\eta^{2}\right) & =\frac{t^{2}}{t^{2}+(N 1+N 2-2)} \\
& =\frac{2.336^{2}}{2.336^{2}+(13+10-2)} \\
& =0.206
\end{aligned}
$$

$\therefore$ There is a large effect.

\section{Results of test 1:}

An independent $t$-test was conducted to compare the scores of two groups. There is a significant difference in the scores of group A and B.

- Group $\mathrm{A}: \mathrm{M}=55.59, \mathrm{SD}=20.10$

- Group B: $\mathrm{M}=37.92, \mathrm{SD}=14.69$

- $\mathrm{t}(21)=2.33, \mathrm{p}=0.029$

- Eta squared $\left(\eta^{2}\right)$ for this data is 0.206 , a large effect size 


\subsection{2 - T-Test Analyses for Test 2}

Test 2 analyzes the differences in the scores when the learning materials are presented to the same group in two different ways. The materials presented to the groups are divided into two parts. One part of the materials presented to both the groups is similar and the other part of the material is different. So the questions based on both parts were segregated and scored. The variation in the results of both the groups is studied and analyzed with a t-test.

The Dif_Mat_Score in group statistics (Table 9) and the independent sample test (Table 10) refers to the difference of similar material and different material.

That is, Dif_Mat_Score is equal to the difference of Similar Material and Different Material.

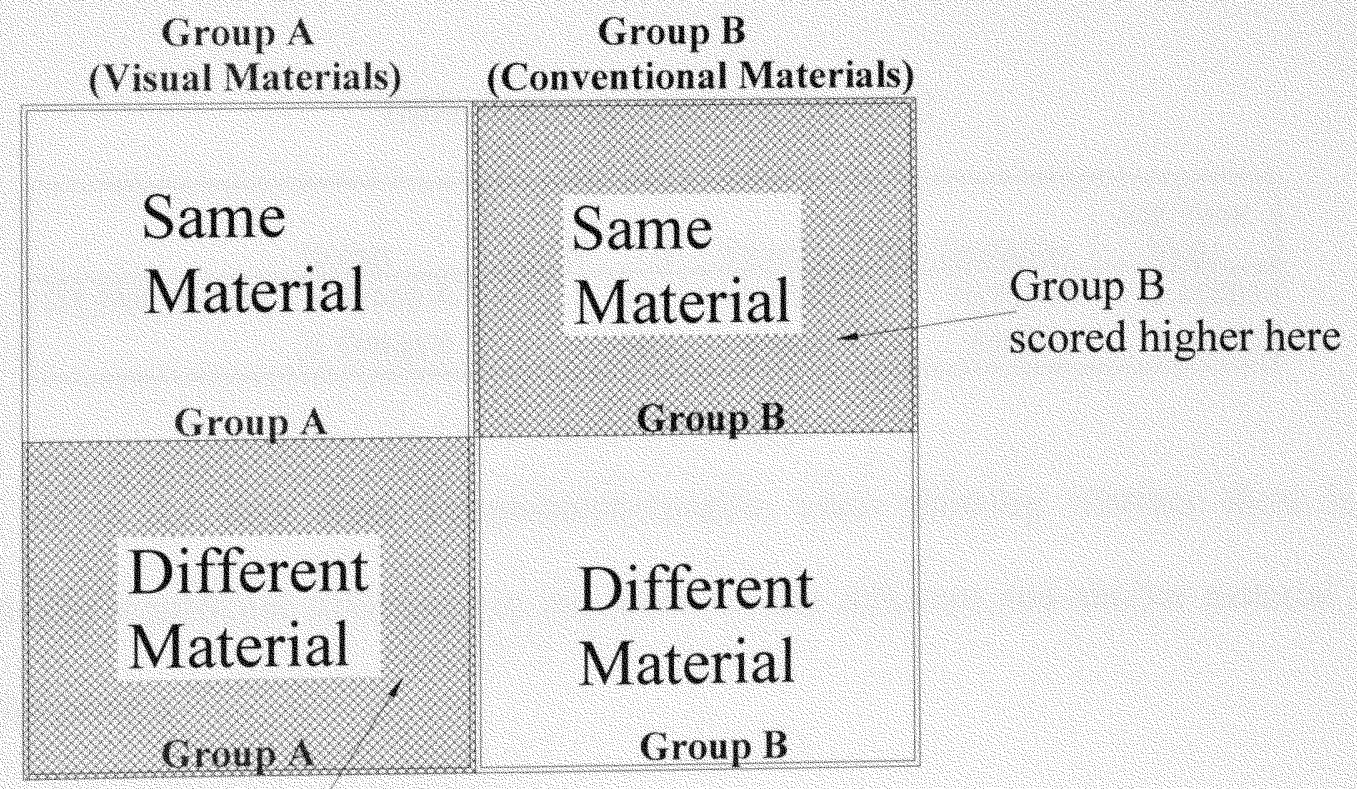

Group A scored higher here

Figure 10: Material presentation and the results of test 
Different material (Figure 10) means that groups A and B had different content which had the same meaning that was presented differently. Same material (Figure 10) means that both the group had same material which was presented almost similarly.

From Table 9: Group A's Mean = -5.153.

$$
\text { Group B's Mean }=8.66
$$

The negative mean value of group A reflects the higher score in different material (since Dif_Mat_Score $=$ Similar Material - Different Material) Group A did well in the different material part. Group B positive mean reflects a higher score in the similar material part. Thus, it shows that the different material (i.e., completely visual for group $\mathrm{A}$ and conventional for group B) presented to the group makes a difference. Group A scored higher than group B.

Table 9: Group statistics for test 2

\begin{tabular}{|ll|r|r|r|r|}
\hline & Group & $N$ & Mean & Std. Deviation & $\begin{array}{c}\text { Std. Error } \\
\text { Mean }\end{array}$ \\
\hline Dif_Mat_Score & 1 Group A & 13 & -5.1531 & 10.70505 & 2.96905 \\
& 2 Group B & 10 & 8.6650 & 7.99979 & 2.52976 \\
\hline
\end{tabular}

Table 10 is the data from independent-samples t-test showing whether there is a statistically significant difference in the scores of the different and similar material for both the groups. 
Table 10: Independent samples test for test 2

\begin{tabular}{|c|c|c|c|c|c|c|c|c|c|c|}
\hline & \multicolumn{2}{|c|}{$\begin{array}{l}\text { Levene's Test } \\
\text { for Equality of } \\
\text { Variances }\end{array}$} & \multicolumn{7}{|c|}{ t-test for Equality of Means } \\
\hline & & \multirow[b]{2}{*}{$\mathrm{F}$} & \multirow[b]{2}{*}{ Sig. } & \multirow[b]{2}{*}{$\mathrm{t}$} & \multirow[b]{2}{*}{ df } & \multirow{2}{*}{$\begin{array}{l}\text { Sig. (2- } \\
\text { tailed) }\end{array}$} & \multirow{2}{*}{$\begin{array}{c}\text { Mean } \\
\text { Differe } \\
\text { nce }\end{array}$} & \multirow{2}{*}{$\begin{array}{c}\text { Std. } \\
\text { Error } \\
\text { Differe } \\
\text { nce }\end{array}$} & \multicolumn{2}{|c|}{$\begin{array}{c}95 \% \\
\text { Confidence } \\
\text { Interval of the } \\
\text { Difference }\end{array}$} \\
\hline & & & & & & & & & Upper & Lower \\
\hline $\begin{array}{l}\text { Dif_Mat_ } \\
\text { Score }\end{array}$ & $\begin{array}{l}\text { Equal } \\
\text { variances } \\
\text { assumed } \\
\text { Equal } \\
\text { variances } \\
\text { not } \\
\text { assumed }\end{array}$ & .482 & .495 & -3.408 & 20.99 & .002 & -13.81 & 4.054 & -22.24 & -5.386 \\
\hline
\end{tabular}

- The Sig. value ( $\mathrm{p}$-value) for Levene's test is 0.495 . So, variances are equal.

- The Sig. value ( $\mathrm{p}$-value) for $\mathrm{t}$-test is 0.003 . So, there is statistically significant difference in Dif_Mat_Score for group A \& B. Group B has statistically higher mean score on Dif_Mat_Score.

- The $95 \%$ confidence interval ranges from -22.24 to -5.386 . So, the two means are significantly different from each other.

- Calculating the effect size for independent-samples t-test:

From the independent sample table, $\mathrm{t}=-3.408$

$$
\text { Eta squared } \begin{aligned}
\left(\eta^{2}\right) & =\frac{t^{2}}{t^{2}+(N 1+N 2-2)} \\
& =\frac{(-3.408)^{2}}{(-3.408)^{2}+(13+10-2)} \\
& =0.356
\end{aligned}
$$

$\therefore$ There is a large effect. 


\section{Results of test 2:}

An independent T-test was conducted to compare the scores of two groups. There is a significant difference in the scores of group $\mathrm{A}$ and $\mathrm{B}$.

- Group A: $\mathrm{M}=-5.15, \mathrm{SD}=10.70$

- Group B: $\mathrm{M}=8.66, \mathrm{SD}=7.99$

- $\mathrm{t}(21)=-3.408, \mathrm{p}=.003$

- Eta squared $\left(\eta^{2}\right)$ for this data is 0.356 , a large effect size.

\subsection{3 - T-Test Analyses for Test 3}

A few specific questions which were presented to both the groups in a similar manner are selected and the results of the students for these questions are analyzed.

Q1, Q2 and Q3 (Table 11) refer to the three questions which were selected for analyses. The mean of all the three questions is higher in group A than in group B. This shows that the group A students secured more marks in the three questions. This can be observed in the group statistics table 11.

Table 11: Group statistics for test 3

\begin{tabular}{|rr|r|r|r|r|}
\hline & & & & & \\
Q1 & Group & $\mathrm{N}$ & Mean & Std. Deviation & $\begin{array}{c}\text { Std. Error } \\
\text { Mean }\end{array}$ \\
\hline & 1 Group A & 13 & $69.23 \%$ & $48.038 \%$ & $13.323 \%$ \\
Q2 & 1 Group B & 10 & $30.00 \%$ & $48.305 \%$ & $15.275 \%$ \\
& 1 Group A & 13 & $84.62 \%$ & $37.553 \%$ & $10.415 \%$ \\
Q3 & 2 Group B & 10 & $40.00 \%$ & $51.640 \%$ & $16.330 \%$ \\
& 1 Group A & 13 & $53.85 \%$ & $51.887 \%$ & $14.391 \%$ \\
& 2 Group B & 10 & $30.00 \%$ & $48.305 \%$ & $15.275 \%$ \\
\hline
\end{tabular}


Table 12 is the data from independent-samples $t$-test showing whether there is a statistically significant difference in the scores of the three questions. From the table it cab be observed that there is not much statistical significance in Q1 and Q3. Significance can be observed in Q2.

Table 12: Independent samples test for test 3

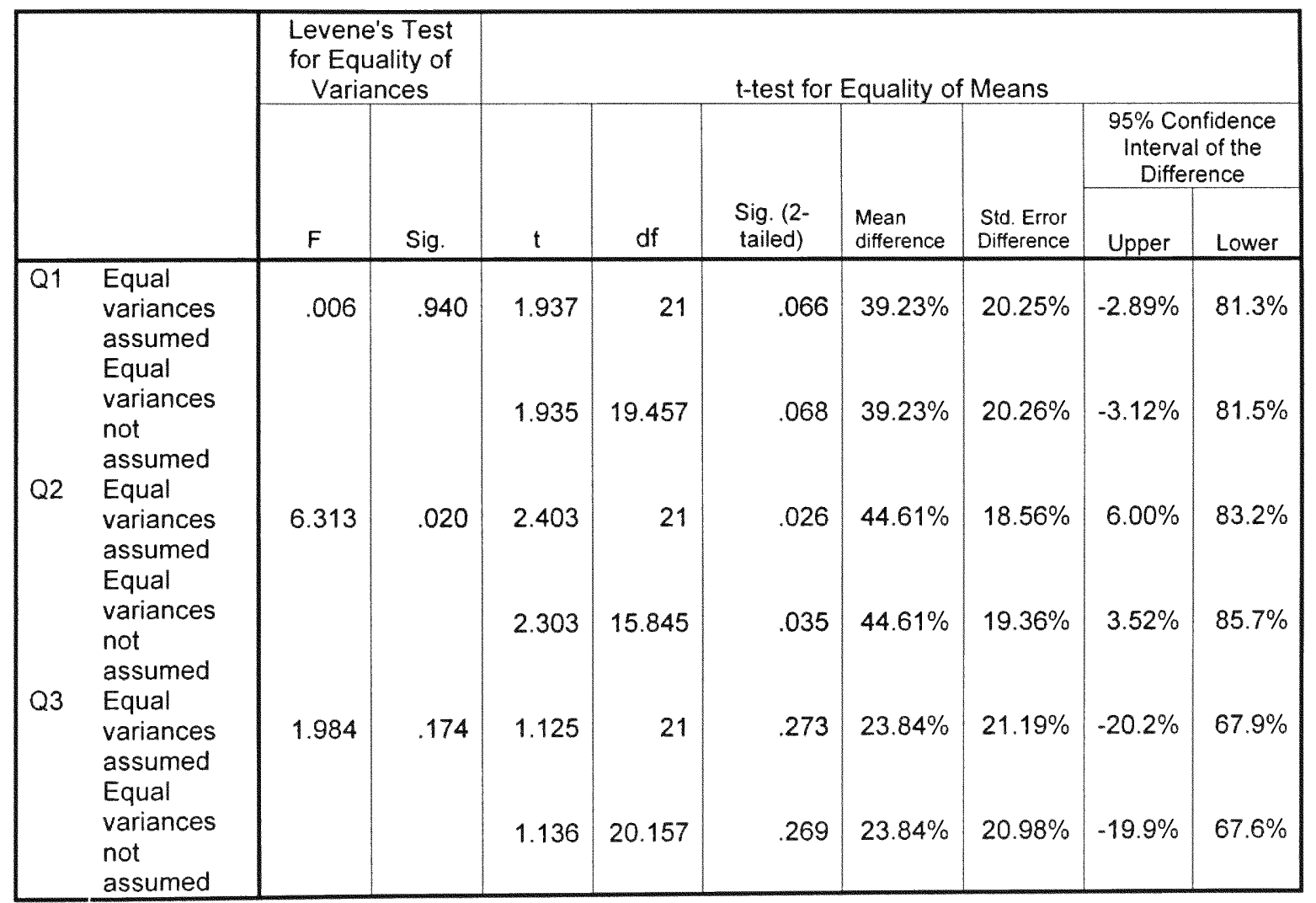

- The Sig. value for Q1 is .94 which is greater than .05. So, the first line in the table which refers to Equal variance assumed should be considered. The Sig. value for Q2 is .020 which is less than .05. So, the fourth line in the table which refers to Equal variance not assumed should be considered. The Sig. value for Q3 is .17 
which is greater than .05 . So, the fifth line in the table which refers to Equal variance assumed should be considered.

- For Q1 and Q3, p-value > 0.05 for t-test and hence there is no statistically significant difference in Q1 or Q3 for group A \& B. In the case Q2, p $<0.05$ and so, there is a statistically significant difference in Q2 for group A \& B.

- For Q2, the $95 \%$ confidence interval ranges from $3.52 \%$ to $85.708 \%$. So, the two means are significantly different from each other.

- Calculating the effect size for independent-samples t-test:

From the independent sample table, $\mathrm{t}=2.303$

$$
\text { Eta squared } \begin{aligned}
\left(\eta^{2}\right) & =\frac{t^{2}}{t^{2}+(N 1+N 2-2)} \\
& =\frac{2.303^{2}}{2.303^{2}+(13+10-2)} \\
& =0.20
\end{aligned}
$$

$\therefore$ There is a large effect.

\section{Results of test 2:}

An independent T-test was conducted to compare the scores of two groups. There is a significant difference in the scores of group A and B.

- Group A:

$$
\begin{aligned}
& \mathrm{Q} 1: \mathrm{M}=69.23 \%, \mathrm{SD}=48.03 \% \\
& \mathrm{Q} 2: \mathrm{M}=84.62 \%, \mathrm{SD}=37.55 \%
\end{aligned}
$$


$\mathrm{Q} 3: \mathrm{M}=53.85 \%, \mathrm{SD}=51.88 \%$

- Group B:

$\mathrm{Q} 1: \mathrm{M}=30.00 \%, \mathrm{SD}=48.30 \%$

$\mathrm{Q} 2: \mathrm{M}=40.00 \%, \mathrm{SD}=51.64 \%$

Q3: $\mathrm{M}=30.00 \%, \mathrm{SD}=48.30 \%$

- Q2: $\mathrm{t}(15.84)=2.30, \mathrm{p}=0.035$

- Eta squared $\left(\eta^{2}\right)$ for this data is 0.20 , a large effect size

The magnitude of the difference in the means is big (eta squared $=0.20$ ).

\subsection{SUMMARY}

This chapter summarizes that addressing prior knowledge and learning style will help improve student's concept learning process. Upon the analyses of the student's t-test which are considered in three different perspectives it has been proved that there is a significant difference between them and their means indicated that group A's performance is better than group B's performance. 


\section{CHAPTER 5}

\section{CONCLUSIONS AND FURTHER WORK}

\subsection{CONCLUSION}

This thesis deals with the students' concept learning process and the factors influencing it. This research is build upon the previous work in fields of AEC (Architecture, Engineering, Construction), concept mapping and pedagogical theories. In the course of this work previous literature was examined and aspects such as concept mapping, prior knowledge and learning style theories were discussed in detail in the literature review. The problems associated with the students' concept learning process considering the impact of prior knowledge and learning styles were not addressed till date. These factors were addressed here taking the green building. Green building has concepts from different disciplines and it is difficult for the students in a multidisciplinary setting to understand them. This thesis aimed at addressing all these aspects and giving a possible solution.

The procedure discussed in the thesis should be implemented in order to bring all the students to a common understanding. Addressing prior knowledge and learning styles while teaching concepts is important because a successful collaborative output can be observed if every student involved has a common understanding. A group of students were tested by giving study material tailored to their learning styles and prior knowledge. In the process prior knowledge and learning style of each student were given priority. 
The results of the tests rejected the null hypothesis $\left(\mathrm{H}_{0}: \mu_{\mathrm{a}} \leq \mu_{\mathrm{b}}\right)$ by showing that both prior knowledge and learning styles of the students will help them learn concepts better.

In conclusion, giving importance and addressing a student's prior knowledge and learning style will be beneficial in facilitating the concept learning process of a green building.

\subsection{FURTHER WORK}

Further study can be focused on the concept presentation methods. There are both abstract and concrete concepts. The concepts of green building - structural insulated panels (SIPs) are concrete, they can be represented without much difficulty (with images, figures and concept maps). But there are some concepts which cannot be shown in a concrete manner; they are called the abstract concepts. The study did not give a solution for presenting abstract concepts in visually rich representations. Methods of representing the abstract concepts to the students are yet to be studied.

While conducting the test to the groups (A and B), guidance (step-by-step plan) was provided to both of them, telling them which concept to focus more and which concept to focus less. It should be observed if there is any difference in the student's concept learning if guidance is not provided in one group and provided in the other. How students perform in a non guided teaching environment? Will there be any difference when students are guided by a plan? All these aspects can be studied in the future. 


\section{REFERENCES}

Ausbel, D. (1968). "Educational Psychology: A cognitive view." Holt, Rinehart and Winston, New York.

Borrego, M., Newswander, L., McNair, D. L (2007). "Special Session - Applying theories of interdisciplinary collaboration in research and teaching practice." $37^{\text {th }}$ ASEE/IEEE Frontiers in Education Conference.

Brown, L.A., Bransford, D. J., Cocking, R. R. (2003). "How People Learn: Brain, Mind, Experience and School." National Academy Press.

Bright, C., Lindsay, E., Lowe, D., Murray, S., Liu, D. (2008). "Factors that impact learning outcomes in remote laboratories." World Conference on Educational Multimedia, Hypermedia and telecommunications (EDMEDIA), Vienna, Austria.

Clemons, S. (2004). "Developing on-line courses for visual/kinesthetic learners: A case studey." International Journal of Instructional Technology and Distance Learning, Vol. 1 No. 11, 51-62.

Cohen, J. (1988). "Statistical power analysis for the behavioral sciences." Hillsdale, NJ: Erlbaum.

Committee on Undergraduate Science Education, Misconceptions as Barriers to Understanding Science. Science Teaching Reconsidered: A Handbook. (1997). National Academy Press.

Coffield, F., Moseley, D., Hall, E., and Ecclestone, K. (2004). "Should we be using learning styles? What research has to say to practice." Learning and Skills Research Centre.

Corbett, S. S., and Smith, W. H. (1984). "Identifying student learning styles: Proceed with caution!" The Modern Language Journal, 68(3, 212-221).

Dunn, R., Beaudry, J., and Klavas, A. 1989. "Survey of research on learning styles." Educational Leadership.

Dunn, R., and Dunn, K. (1978). "Teaching students through their individual learning styles: A practical approach." Reston publishing, Reston, VA.

Ertl, B., and Mandl, H. (2006). "Effects of an individual's prior knowledge on collaborative knowledge construction and individual learning outcomes in videoconferencing." International Conference on Learning Sciences, Proceedings of the $7^{\text {th }}$ international conference on Learning Sciences, International Society of Learning sciences, Bloomington, Indiana, 161-167. 
Ewel, C. K. (2000). "Natural resource management: The need for interdisciplinary collaboration." 716-722.

Felder, M. R., and Silverman, K., L. (1988). "Learning and Teaching Styles In Engineering Education." Engineering Education, 78(7), 674-681.

Fleming, N. D., and Mills, C. (1992). "Not Another Inventory, Rather a Catalyst for Reflection." To Improve the Academy. Vol. II, 137-155.

Fleming, N (2001). "VARK - a guide to learning styles." < www.vark-learn.com>.

Fleming, N and Baume, D (2006). "Learning Styles Again: VARKing up the right tree!" Educational Developments, SEDA Ltd, Issue 7.4.

Fruchter, R. (1999). "A/E/C Teamwork: A collaborative design and learning space." Journal of computing in civil engineering, Vol. 13, No. 4, 261-269.

Glaserfeld, E.V. (1984). "An introduction to radical constructivism." In P. Watlawick (Ed.), The invented reality. New York: W.W. Norton.

Gokhale, A.A. (1995). "Collaborative learning enhances critical thinking." Journal of Technology Education, Vol. 7, No. 1.

Griggs, S. A. (1991). "Learning Styles Counseling." ERIC Clearinghouse and Personal services, Ann Arbor, MI.

Hall, P., and Weaver, L. (2001). "Interdisciplinary education and teamwork: a long and winding road." 867-875.

Ilal, E. M (2007). "The quest for integrated design system: A brief survey of past and current efforts."

Lovelace, M. K. (2005). "Meta-Analysis of Experimental Research Based on the Dunn and Dunn Model." The Journal of Educational Research, Vol. 98, No. 3, 176-183.

Kujawa, S., and Huske, L. (1995). "Strategic Teaching and Reading Project Guidebook." North Central Regional Educational Laboratory, rev. ed, Naperville, Illinois.

Keefe, J. W. (1979). "Learning style: An overview." In NASSP's Student learning styles: Diagnosing and prescribing programs (pp. 1-17). Reston, VA: National Association of Secondary School Principals.

Lucas, R. W. (2003). "The creative training idea book: Inspired tips and techniques for engaging and effective learning". 
Miller, J. K., Koury, K., Fitzgerald, Gail., Hollingsead, C., Mitchem, K., Tsai, H. (2007). "Concept mapping as a research tool to evaluate conceptual change and learning gains."

Nefstead, E. W. (1998). "An application of learning style theory to undergraduate instruction in accounting: A Minnesota example." American Agricultural Economics Association Annual Meeting, Salt Lake City, Utah.

Nickerson, V. J., Corter, E. J., Esche, K. S., Chassapis, C. (2005). "A model for evaluating the effectiveness of remote engineering laboratories and simulations in education." Computers \& Education 49 (2007), 708-725.

Novak, J. (1998). "Learning, Creating, and Using Knowledge: Concept Maps as Facilitative Tools in Schools and Corporations." Lawrence Erlbaum Associates, Mahwah, NJ.

Novak, J. D., and Gowin, D. B. (1984). "Learning How to Learn." Cambridge University Press, New York, NY.

Novak, J. D., and Canas A. J. (2006). "The Theory Underlying Concept Maps and How to Construct Them." Florida Institute for Human and Machine Cognition (IHMC).

O'Brien, W., Soibelman, L., Elvin, G. (2003). "Collaborative Design Processes: An active-and reflective-learning course in multidisciplinary collaboration." Journal of Construction Education, Vol. 8, No. 2, 78-93.

O'Donnell, A.M., and Dansereau, D. F. (2000). "Interactive effects of prior knowledge and material format on cooperative teaching." Journal of Experimental Education, 68, 101-118.

Pallant, J. (2001). "SPSS survival manual." Statistical techniques to compare groups -Ttests. Open University Press, Celtic court, Buckingham.

Primo, R., Schultz, E. S., Li, M., and Shavelson, J. R. (1998). "Comparison of the reliability and validity of scores from two concept-mapping techniques." Stanford University, AERA Annual Meeting, San Diego, CA.

Primo, R. (2004). "Examining concept maps as an assessment tool." School of education, Stanford University.

Resnick, L.B. (1983). "Mathematics and science learning: A new conception." Science, 220, 477-478.

Roschelle, J. (1995). "Learning in Interactive Environments: Prior knowledge and New Experience." Public Institutions for Personal Learning: Establishing a Research Agenda, The American Association of Museums, San Francisco, CA. 
Sims, R. Ronald, and Sims, J. Serbrenia (1995). "The Importance of Learning Styles." Learning and learning styles, Greenwood press, Westport, CT.,194.

Sims-Knight, E. J., Upchurch, L. R., Pendergrass, N., Meressi, T., Fortier, P., Tchimev, P., Vonderhede, R. and Page, M., (2004). "Using Concept maps to assess design process knowledge." $34^{\text {th }}$ ASEE/IEEE Frontiers in Education Conference, Savannah, GA.

Skinner, J. (2001). "Transitioning from multidisciplinary to interdisciplinary education in gerontology and geriatrics." Gerontology and geriatrics education, Vol. 21 (3), The Haworth Press. 


\section{APPENDICES}

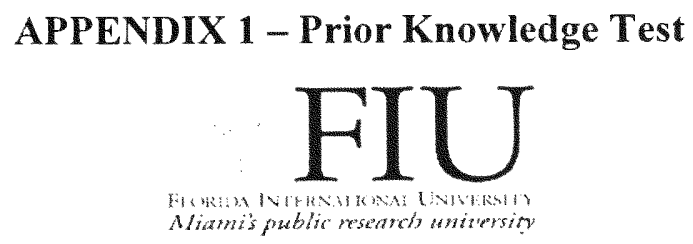

TEST - I

Name

Undergraduate bachelors degree

Each question may have more than one answer from the options. Mark all that apply:

1. What are the characteristics of a Green Building?

$\square$ Similar to a conventional building

$\square$ Energy Efficient and Environmental Friendly

$\square$ A building which looks Green

$\square$ No idea

2. What are Structural Insulated Panels (SIPs)?

Insulation material

Material composed of two outer skins and an inner insulation

Building element

Is not a green building element

No idea

3. What is Life Cycle Cost?

$\square$ Have initial costs, financing costs, operational costs

$\square$ Is a total cost of construction

Is a total cost of the building

$\square$ Treats design decision as investments

$\square$ No idea

4. What is R-value?

A measure of heat

Is the strength of the material

A measure of temperature

Thickness of insulation

Is a measure of thermal resistance (Material's measure of resistance to heat transfer)

$R$ value is the reciprocal of $U$-value

No idea 
5. HVAC is,

$\square$ A mechanical system

A structural system

$\square$ Acronym of Heating, Ventilation and Air Conditioning

A designing element

No idea

6. What is Air-infiltration?

$\square$ Is the amount of air leaking in and out of a building through cracks in it

$\square$ Is used to calculate the air movement.

$\exists$ Is R-value of a system

Is Air tightness

No idea

7. Are there any economic benefits of a SIP?

$\square$ Yes $\square$ No $\square$ No Idea

8. If your answer for the above question is "Yes" then, what are those benefits?

$\square$ Reduce operating costs

Enhance asset value and profits

Low initial cost

$\square$ Optimize life-cycle economic performance

No idea

9. Structural Insulated Panels (SIPs),

$\square$ Have high U-value

$\square$ Have high R-value

Are easy to handle while construction

Energy efficient

$\square$ Used for exterior building envelop

$\square$ High performance panelized building system

$\checkmark$ No idea

10. Structural Insulated Panels (SIPs) have,

$\square$ Design flexibility

$\square$ Thermal efficiency

$\square$ Seismic strength

$\square$ No idea

11. SIPs have,

$\square$ Great resistance against buckling and bending

$\square$ Low resistance against buckling and bending

$\square$ Highly resistant to local loading

$\square$ Not resistant to local loading 
$\square$ Can resist earthquake and hurricane forces

$\square$ Cannot resist earthquake and hurricane forces

No idea

12. The higher the R-value,

$\square$ The lower the insulation effectiveness

$\square$ The greater the insulation effectiveness

$\square$ No idea

13. SIPs are particularly suitable for extreme climate zones because

$\square$ of their high insulation and R-value

$\square$ Their facings are of wood

$\square$ of their high U-value

$\square$ No idea

14. SIPs have lower Life Cycle Cost (LCC)

$\square$ Yes $\square$ No $\quad \square$ No Idea

15. SIPs have low operation and maintenance cost

$\square$ True

$\square$ False

$\square$ No Idea

16. SIPs are

$\square$ Easy to handle at the job site

$\square$ Can be handled with fork lifts

$\square$ Fast to construct

Difficult to construct

No idea

17. SIPs have design flexibility

$\square$ True $\square$ False $\square$ No Idea

18. The thermal performance of SIP is good
True
$\square$ False
$\square$ No Idea

19. SIPs can have finishes (aesthetic treatment) such as,

$\square$ Paint

$\square$ Bricks and Stones

$\square$ Stucco, lap Siding, Gypsum wall board or dry wall

$\square$ Tiles

$\square$ No idea

20. SIPs require mechanical ventilation

$\square$ Yes $\square$ No $\square$ No Idea 


\section{APPENDIX 2 - Learning Style Questionnaire}

\section{The VARK Questionnaire}

\section{How Do I Learn Best?}

Choose the answer which best explains your preference and circle the letter(s) next to it. Please circle more than one if a single answer does not match your perception. Leave blank any question that does not apply.

You have a problem with your knee. You would prefer that the doctor:

Gave you a web address or something to read about it.

Used a plastic model of a knee to show what was wrong.

Described what was wrong.

Showed you a diagram of what was wrong.

You are not sure whether a word should be spelled 'dependent' or 'dependant'. You would:

Write both words on paper and choose one.

Think about how each word sounds and choose one.

Find it in a dictionary.

See the words in your mind and choose by the way they look.

You are about to purchase a digital camera or mobile phone. Other than price, what would most influence your decision?

The salesperson telling me about its features.

Reading the details about its features.

Trying or testing it

It is a modern design and looks good.

\footnotetext{
(C) Copyright Version 7.0 (2006) held by Neil D. Fleming, Christchurch, New Zealand and Charles C. Bonwell, Green Mountain Falls, Colorado 80819 U.S.A.
} 
You have finished a competition or test and would like some feedback. You would like to have feedback:

Using examples from what you have done.

Using a written description of your results.

From somebody who talks it through with you.

Using graphs showing what you had achieved.

You are going to choose food at a restaurant or cafe. You would:

Choose from the descriptions in the menu.

r Choose something that you have had there before.

Listen to the waiter or ask friends to recommend choices.

Look at what others are eating or look at pictures of each dish.

Other than price, what would most influence your decision to buy a new non-fiction book?

A friend talks about it and recommends it.

It has real-life stories, experiences and examples.

$T$ The way it looks is appealing.

Quickly reading parts of it.

You are using a book, $\mathrm{CD}$ or website to learn how to take photos with your new digital camera. You would like to have:

Clear written instructions with lists and bullet points about what to do.

Diagrams showing the camera and what each part does.

A chance to ask questions and talk about the camera and its features.

Many examples of good and poor photos and how to improve them. 
I like websites that have:

Things I can click on, shift or try.

Interesting written descriptions, lists and explanations.

Interesting design and visual features.

Audio channels where I can hear music, radio programs or interviews.

A group of tourists want to learn about the parks or wildlife reserves in your area. You would:

Take them to a park or wildlife reserve and walk with them.

Give them a book or pamphlets about the parks or wildlife reserves.

Talk about, or arrange a talk for them about parks or wildlife reserves.

Show them internet pictures, photographs or picture books.

You have to make an important speech at a conference or special occasion. You would: Make diagrams or get graphs to help explain things.

Gather many examples and stories to make the talk real and practical.

Write out your speech and learn from reading it over several times.

Write a few key words and practice saying your speech over and over.

You are going to cook something as a special treat for your family. You would:

Look through the cookbook for ideas from the pictures.

Use a cookbook where you know there is a good recipe.

Cook something you know without the need for instructions.

Ask friends for suggestions.

Remember a time when you learned how to do something new. Try to avoid choosing a physical skill, e.g. riding a bike. You learned best by:

Watching a demonstration.

$\Gamma$ Listening to somebody explaining it and asking questions. 
Diagrams and charts - visual clues.

Written instructions - e.g. a manual or textbook.

You want to learn a new program, skill or game on a computer. You would:

Use the controls or keyboard.

Follow the diagrams in the book that came with it.

Talk with people who know about the program.

Read the written instructions that came with the program.

Do you prefer a teacher or a presenter who uses:

Handouts, books, or readings.

Diagrams, charts or graphs.

Question and answer, talk, group discussion, or guest speakers.

Demonstrations, models or practical sessions.

You are helping someone who wants to go to your airport, town centre or railway station. You would:

Tell her the directions.

Write down the directions.

Draw, or give her a map.

Go with her.

You are planning a holiday for a group. You want some feedback from them about the plan. You would:

1 Describe some of the highlights.

Give them a copy of the printed itinerary.

Phone, text or email them.

Use a map or website to show them the places. 


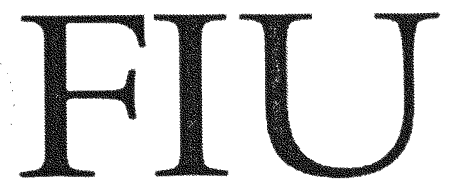

FLORIDA INTERNATIONAL UNIVIRSTYY

Miamis public research university

FINAL TEST

Name

Undergraduate bachelors degree

Answer the following:

Q. What is the material used for the inner core of SIP?

Q. What are the outer panels made up of?

Fill the blanks:

Q. If SIP works like an I-Beam, act as the flanges and the act as the web.

Answer the Following:

Q. Are SIPs highly energy efficient?

$\square$ True $\square$ False $\square$ No Idea

Q. SIPs require mechanical ventilation to preserve indoor air-quality,

$\square$ True $\square$ False $\square$ No Idea

Q. SIPs have chases through which electric wires pass

$\square$ True $\square$ False $\square$ No Idea

Q. SIPs have design flexibility
True
$\square$ False
$\square$ No Idea

Q. The thermal performance of SIP is good
True
$\square$ False
$\square$ No Idea

Q. HRV (Heat Recovery Ventilation) is used in Cold Climates for SIP buildings

$\square$ True

$\square$ False

$\square$ No Idea 
Q. SIP building has less heating and cooling costs as it is air-tight

True

$\square$ False

$\square$ No Idea

Q. Structural Insulated panel (SIP) is a green building material.

$\square$ True $\square$ False $\square$ No Idea

Q. In a seismically active area, some of the panels are designated as shear walls and must be tied to the foundation with hold-downs.

$\square$ True $\square$ False $\square$ No Idea

Each question may have more than one answer from the options. Mark all that apply:

Q. SIPs can have finishes such as,

$\square$ Paint

$\square$ Bricks and Stones

$\square$ Stucco, lap Siding, Gypsum wall board or dry wall

Tiles

Q. What are the advantages of SIP?

$\square$ Highly energy efficient

$\square$ Has high U-value

$\square$ Acts as good insulation

$\square$ Is high performance building panel

Q. SIPs have

$\square$ Lower R-value

$\square$ Moderate R-value

$\square$ Higher R-value

Q. U-value is

$\square$ Equal to $\mathrm{R}$-value

$\mathrm{Deciprocal}$ of R-value

Q. What is R-value?

A measure of heat

Is the strength of the material

A measure of temperature

Thickness of insulation

Is a measure of thermal resistance (Material's measure of resistance to heat transfer)

$\mathrm{R}$ value is the reciprocal of $U$-value

Q. R-value is equal to

(Temp. difference $\mathrm{x}$ Area $\mathrm{x}$ Time)/Heat loss

(Temp. difference $x$ Area $x$ Heat loss)/Time

Temp. difference $x$ Area $x$ Time $x$ Heat loss 
Q. The higher the R-value,

$\square$ The lower the insulation effectiveness

$\square$ The greater the insulation effectiveness

Q. For calculating the R-value of a SIP wall we should consider,

$\square R$ value of the insulation alone

$\square R$ value of SIP facings as well as exterior and interior finishes (sum of the layers of the wall, i.e. the total wall $R$ value)

Q. SIP structures have less energy costs because,

$\square$ They are Air-tight

They are energy efficient

They are constructed with wood

$\square$ Cooling and heating is not required

Q. SIPs have,

$\square$ Great resistance against buckling and bending

$\square$ Low resistance against buckling and bending

$\square$ Highly resistant to local loading

$\square$ Not resistant to local loading

Can resist earthquake and hurricane forces

Cannot resist earthquake and hurricane forces

Q. What is Life Cycle Cost?

$\square$ Evaluates all the financial costs (have initial costs, financing costs, operational costs)

Is a total cost of construction

Is a total cost of the building

$\square$ Treats design decision as investments and is a base for financial decision

Q. SIPs are

$\square$ Easy to handle at the job site

$\square$ Can be handled with fork lifts

Fast to construct

Difficult to construct

Q. What is Air-infiltration?

Is the amount of air leaking in and out of a building through cracks in it

Is used to calculate the air movement.

$\square$ Is R-value of a system

$\square$ Is Air tightness

No idea

Q.Panels are connected edge-to-edge with

$\square$ Splines.

$\square$ Adhesives

$\square$ Fasteners

No idea 


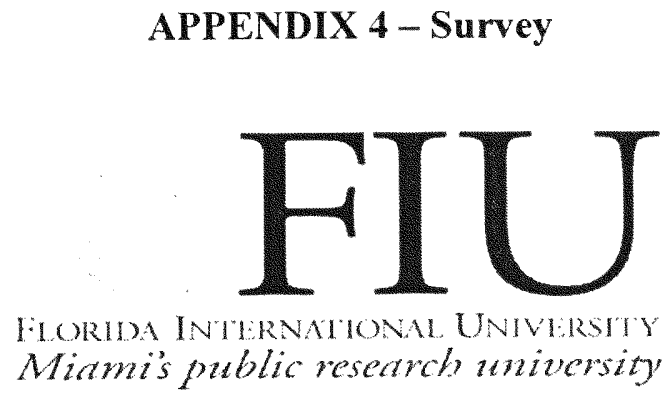

Name:

How would you like to learn new concepts or a subject in your coursework?

$\square$ If the lecture and the study materials are supported with images, figures and graphs.

$\square$ If the lecture and the study materials are presented in an audio-visual format

$\square$ If it is presented as a lecture or in a conventional manner.

$\square$ If it is an interactive session and if it involves group work and case studies. 


\section{CODING:}

Degrees:

Architecture - 1

Civil Engineering - 2

Mechanical Engineering - 3

Construction Management - 4

Others (Business, biology, psychology) -5

\section{Learner types:}

Visual - 1

Auditory - 2

Kinesthetic - 3

Multimodal -4

\section{Groups:}

Group A - 1

Group B - 2

ID - Student's identification

\section{Test 1 results:}

\begin{tabular}{|c|c|c|c|c|c|}
\hline ID & Degree & Group & Learner & Priorknowledge_test & Final_test \\
\hline 1 & 5 & 1 & 1 & $10 \%$ & $84.61 \%$ \\
\hline 2 & 5 & 1 & 1 & $20 \%$ & $76.92 \%$ \\
\hline 3 & 5 & 1 & 1 & $20 \%$ & $90.38 \%$ \\
\hline 4 & 5 & 1 & 1 & $20 \%$ & $74 \%$ \\
\hline 5 & 1 & 1 & 1 & $40 \%$ & $90.38 \%$ \\
\hline 6 & 5 & 1 & 1 & $70 \%$ & $82.69 \%$ \\
\hline 7 & 1 & 1 & 1 & $25 \%$ & $75 \%$ \\
\hline 8 & 1 & 1 & 1 & $20 \%$ & $100 \%$ \\
\hline 9 & 2 & 1 & 1 & $10 \%$ & $85 \%$ \\
\hline 10 & 4 & 1 & 1 & $25 \%$ & $85 \%$ \\
\hline 11 & 2 & 1 & 1 & $80 \%$ & $100 \%$ \\
\hline 12 & 5 & 1 & 3 & $45 \%$ & $98 \%$ \\
\hline 13 & 2 & 1 & 3 & $15 \%$ & $80.76 \%$ \\
\hline
\end{tabular}


Test 2 results:

\begin{tabular}{|c|c|c|c|c|c|}
\hline ID & Degree & Group & Learner & Different_Material & Similar_Material \\
\hline 1 & 5 & 1 & 1 & $81 \%$ & $80.00 \%$ \\
\hline 2 & 5 & 1 & 1 & $72 \%$ & $80.00 \%$ \\
\hline 3 & 5 & 1 & 1 & $94 \%$ & $85.00 \%$ \\
\hline 4 & 5 & 1 & 1 & $84 \%$ & $55 \%$ \\
\hline 5 & 1 & 1 & 1 & $94 \%$ & $85.00 \%$ \\
\hline 6 & 5 & 1 & 1 & $75 \%$ & $85.00 \%$ \\
\hline 7 & 1 & 1 & 1 & $75 \%$ & $75 \%$ \\
\hline 8 & 1 & 1 & 1 & $100 \%$ & $100 \%$ \\
\hline 9 & 2 & 1 & 1 & $81 \%$ & $80 \%$ \\
\hline 10 & 4 & 1 & 1 & $100 \%$ & $80 \%$ \\
\hline 11 & 2 & 1 & 1 & $100 \%$ & $100 \%$ \\
\hline 12 & 5 & 1 & 3 & $100 \%$ & $90 \%$ \\
\hline 13 & 2 & 1 & 3 & $80 \%$ & $74.00 \%$ \\
\hline
\end{tabular}

Test 3 results:

\begin{tabular}{|c|c|c|c|c|c|c|}
\hline ID & Degree & Group & Learner & Q1 & Q2 & Q3 \\
\hline 1 & 5 & 1 & 1 & $0 \%$ & $100 \%$ & $0 \%$ \\
\hline 2 & 5 & 1 & 1 & $0 \%$ & $100 \%$ & $100 \%$ \\
\hline 3 & 5 & 1 & 1 & $100 \%$ & $100 \%$ & $0 \%$ \\
\hline 4 & 5 & 1 & 1 & $0 \%$ & $0 \%$ & $100 \%$ \\
\hline 5 & 1 & 1 & 1 & $100 \%$ & $100 \%$ & $100 \%$ \\
\hline 6 & 5 & 1 & 1 & $100 \%$ & $100 \%$ & $100 \%$ \\
\hline 7 & 1 & 1 & 1 & $0 \%$ & $100 \%$ & $0 \%$ \\
\hline 8 & 1 & 1 & 1 & $100 \%$ & $100 \%$ & $100 \%$ \\
\hline 9 & 2 & 1 & 1 & $100 \%$ & $100 \%$ & $0 \%$ \\
\hline 10 & 4 & 1 & 1 & $100 \%$ & $100 \%$ & $0 \%$ \\
\hline 11 & 2 & 1 & 1 & $100 \%$ & $100 \%$ & $100 \%$ \\
\hline 12 & 5 & 1 & 3 & $100 \%$ & $100 \%$ & $0 \%$ \\
\hline 13 & 2 & 1 & 3 & $100 \%$ & $0 \%$ & $100 \%$ \\
\hline
\end{tabular}




\section{CODING:}

\section{Degrees:}

Architecture - 1

Civil Engineering - 2

Mechanical Engineering - 3

Construction Management - 4

Others (Business, biology, psychology) -5

\section{Learner types:}

Visual - 1

Auditory - 2

Kinesthetic - 3

Multimodal -4

\section{Groups:}

Group A - 1

Group B - 2

ID - Student's identification

\section{Test 1 results:}

\begin{tabular}{|c|c|c|c|c|c|}
\hline ID & Degree & Group & Learner & Priorknowledge_test & Final_test \\
\hline 14 & 5 & 2 & 1 & $20 \%$ & $75 \%$ \\
\hline 15 & 1 & 2 & 1 & $50 \%$ & $65 \%$ \\
\hline 16 & 5 & 2 & 1 & $50 \%$ & $90.38 \%$ \\
\hline 17 & 2 & 2 & 1 & $25 \%$ & $76.92 \%$ \\
\hline 18 & 1 & 2 & 1 & $20 \%$ & $53.07 \%$ \\
\hline 19 & 1 & 2 & 1 & $40 \%$ & $80 \%$ \\
\hline 20 & 1 & 2 & 1 & $10 \%$ & $69.23 \%$ \\
\hline 21 & 4 & 2 & 1 & $20 \%$ & $57.69 \%$ \\
\hline 22 & 2 & 2 & 3 & $50 \%$ & $70 \%$ \\
\hline 23 & 1 & 2 & 3 & $40 \%$ & $66.92 \%$ \\
\hline
\end{tabular}




\section{Test 2 results:}

\begin{tabular}{|c|c|c|c|c|c|}
\hline ID & Degree & Group & Learner & Different_Material & Similar_Material \\
\hline 14 & 5 & 2 & 1 & $97 \%$ & $100 \%$ \\
\hline 15 & 1 & 2 & 1 & $65 \%$ & $75 \%$ \\
\hline 16 & 5 & 2 & 1 & $88 \%$ & $100.00 \%$ \\
\hline 17 & 2 & 2 & 1 & $78 \%$ & $95.00 \%$ \\
\hline 18 & 1 & 2 & 1 & $72 \%$ & $95.00 \%$ \\
\hline 19 & 1 & 2 & 1 & $80 \%$ & $85 \%$ \\
\hline 20 & 1 & 2 & 1 & $70 \%$ & $82.00 \%$ \\
\hline 21 & 4 & 2 & 1 & $75 \%$ & $80.00 \%$ \\
\hline 22 & 2 & 2 & 3 & $100 \%$ & $95 \%$ \\
\hline 23 & 1 & 2 & 3 & $81 \%$ & $85.00 \%$ \\
\hline
\end{tabular}

\section{Test 3 results:}

\begin{tabular}{|c|c|c|c|c|c|c|}
\hline ID & Degree & Group & Learner & Q1 & Q2 & Q3 \\
\hline 14 & 5 & 2 & 1 & $100 \%$ & $100 \%$ & $100 \%$ \\
\hline 15 & 1 & 2 & 1 & $0 \%$ & $100 \%$ & $0 \%$ \\
\hline 16 & 5 & 2 & 1 & $100 \%$ & $0 \%$ & $100 \%$ \\
\hline 17 & 2 & 2 & 1 & $0 \%$ & $0 \%$ & $0 \%$ \\
\hline 18 & 1 & 2 & 1 & $0 \%$ & $0 \%$ & $0 \%$ \\
\hline 19 & 1 & 2 & 1 & $0 \%$ & $0 \%$ & $0 \%$ \\
\hline 20 & 1 & 2 & 1 & $0 \%$ & $0 \%$ & $0 \%$ \\
\hline 21 & 4 & 2 & 1 & $0 \%$ & $100 \%$ & $0 \%$ \\
\hline 22 & 2 & 2 & 3 & $100 \%$ & $100 \%$ & $100 \%$ \\
\hline 23 & 1 & 2 & 3 & $0 \%$ & $0 \%$ & $0 \%$ \\
\hline
\end{tabular}

